Florida International University

FIU Digital Commons

3-29-2019

\title{
Construction Workers' Health and Safety During Post Disaster Reconstruction Phase: A Case Study in Nepal
}

S M Jamil Uddin

Florida International University, suddi004@fiu.edu

Follow this and additional works at: https://digitalcommons.fiu.edu/etd

Part of the Construction Engineering and Management Commons

\section{Recommended Citation}

Uddin, S M Jamil, "Construction Workers' Health and Safety During Post Disaster Reconstruction Phase: A Case Study in Nepal" (2019). FIU Electronic Theses and Dissertations. 4011.

https://digitalcommons.fiu.edu/etd/4011

This work is brought to you for free and open access by the University Graduate School at FIU Digital Commons. It has been accepted for inclusion in FIU Electronic Theses and Dissertations by an authorized administrator of FIU Digital Commons. For more information, please contact dcc@fiu.edu. 


\section{FLORIDA INTERNATIONAL UNIVERSITY}

Miami, Florida

CONSTRUCTION WORKERS' HEALTH AND SAFETY DURING POST DISASTER RECONSTRUCTION PHASE: A CASE STUDY IN NEPAL

A thesis submitted in partial fulfillment of

the requirements for the degree of

MASTER OF SCIENCE

in

CONSTRUCTION MANAGEMENT

by

S M Jamil Uddin 
To: Dean John L. Volakis

College of Engineering and Computing

This thesis, written by S M Jamil Uddin, and entitled Construction Workers' Health and Safety during Post Disaster Reconstruction Phase: A Case Study in Nepal, having been approved in respect to style and intellectual content, is referred to you for judgment.

We have read this thesis and recommend that it be approved.

N. Emel Ganapati

Jose A. Faria

Nipesh Pradhananaga, Major Professor

Date of Defense: March 29, 2019

The thesis of S M Jamil Uddin is approved.

Dean John L. Volakis
College of Engineering and Computing

College of Engineering and Computing

Andrés G. Gil

Vice President for Research and Economic Development and Dean of the University Graduate School

Florida International University, 2019 
C Copyright 2019 by S M Jamil Uddin

All rights reserved. 


\section{DEDICATION}

To My Parents and My Beloved Wife. 


\section{ACKNOWLEDGMENTS}

First of all, I thank the Almighty Allah (SW) for His endless mercy and blessings upon me. I would like to express my sincerest gratitude to my advisor Dr. Nipesh Pradhananga for his continuous support and guidance during my graduate study. This thesis would not have been possible without his expert supervision and direction.

I would also like to thank the members of my committee, Dr. Jose Faria and Dr. Emile Ganapati for their support during my research and for finding time in their busy schedule for my dissertation.

I would also like to thank Ms. Kiran Shilpakar, Ms. Anjana Karki, Mr. Pramesh Bhaila, Mr. Shivahari Pokhrel, and Mr. Shairan Twanabasu, undergraduate students of the Department of Civil Engineering at Khwopa Engineering College, Nepal for conducting the interviews with the local participants and transcribing the interviews. Special thanks to Mr. Jeetendra Prajapati for allowing me to access his data set and using it for my thesis. A sincere thanks to all my friends and colleagues who have kept supporting me throughout my grad life. Their influence on my learning process is worth mentioning.

Last but not the least, I would like to thank my beloved wife, Mahzabin Tamanna, for not only her continuous support throughout my rigorous journey of the graduate studies but also for being beside me during my ups and downs and the worst moments of my life. 


\begin{abstract}
OF THE THESIS
CONSTRUCTION WORKERS' HEALTH AND SAFETY DURING POST DISASTER RECONSTRUCTION PHASE: A CASE STUDY IN NEPAL

by
\end{abstract}

S M Jamil Uddin

Florida International University, 2019

Miami, Florida

Professor Nipesh Pradhananga, Major Professor

The understanding of the concept of construction workers' health and safety during the post-disaster reconstruction (PDR) phase is still unexplored. The objectives of this study are: (1) to identify a knowledge gap in the literature through systematic literature review, (2) to find out the similarities and dissimilarities between regular construction and post disaster reconstruction and (3) to find out factors that affect the health and safety of the workers during PDR. To achieve the objectives, a qualitative data set was collected from a secondary source. The data set includes 38 in-depth semi-structured interviews that were conducted with a range of stakeholders, including owners, general contractors, government officials, safety supervisors, engineers and construction workers in the context of the Nepal Earthquake 2015. The findings of this study shows a significant knowledge gap in the literature and also pointed out issues such as debris management, the participation of community people, using unskilled workers, immigrant workers as some of the factors which play a vital role from the safety aspect. Finally, the findings of this study introduce workers' health and safety as an important issue in PDR planning. 


\section{TABLE OF CONTENTS}

CHAPTER

PAGE

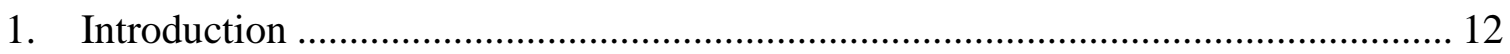

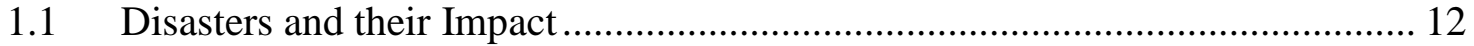

1.2 Recovery from the Natural Disasters ............................................................ 16

1.3 Post Disaster Reconstruction (PDR) ....................................................... 17

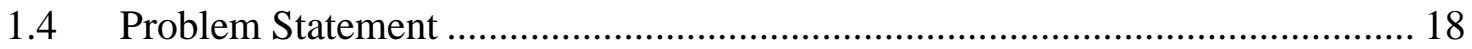

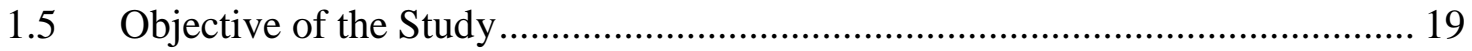

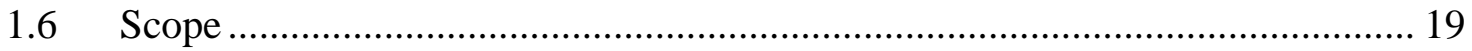

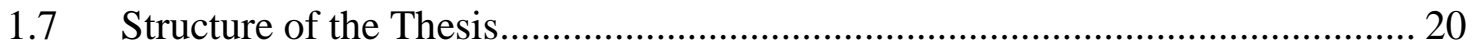

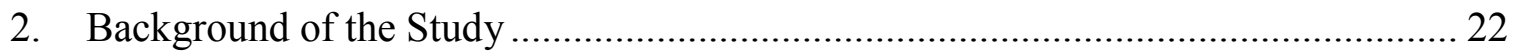

2.1 Previous Works Related to Post Disaster Reconstruction (PDR) …………....... 22

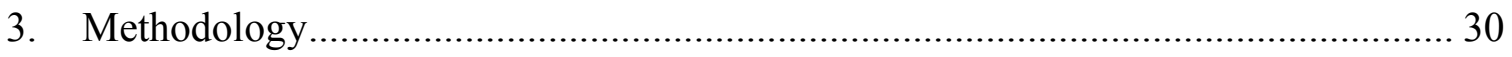

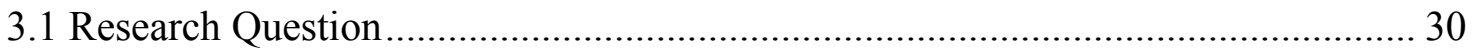

3.2 Systematic Literature Review ………................................................... 30

3.2.1 Level 1: Identification of Target Articles ................................................ 32

3.2.2. Level 2: Screening of the Target Articles ................................................. 32

3.2.3. Level 3: Qualitative Analysis............................................................... 33

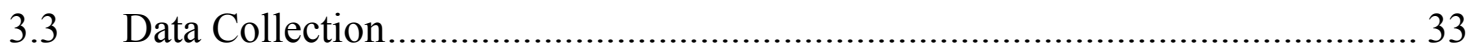

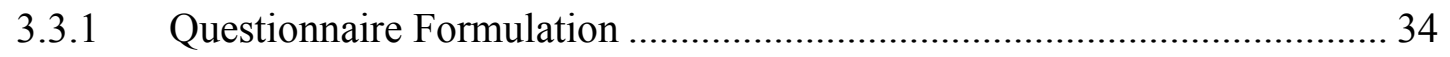

3.3.2 Process of Conducting Interviews ......................................................... 34

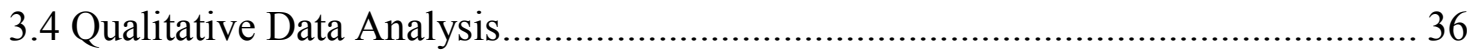

3.4.1 Theme Identification using Nodes ......................................................... 38

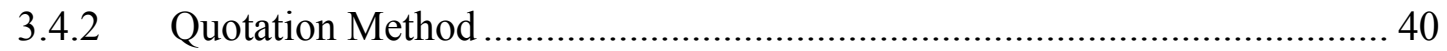

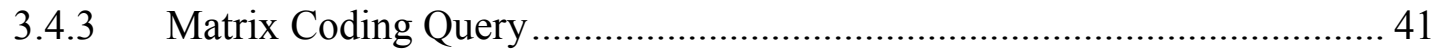

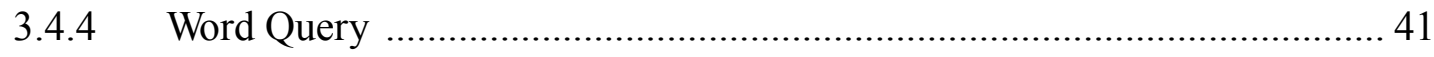

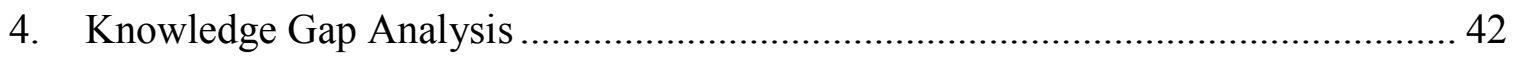

$4.1 \quad$ Objective and Scope ............................................................................... 43

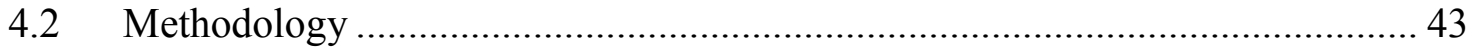

4.3 Understanding Post-disaster Reconstruction (PDR) Phase ................................ 45

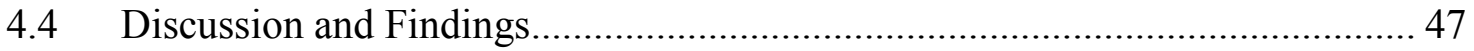

4.4.1 Health and Safety with Debris Management ............................................. 49 
4.4.2 Participation of Community People ....................................................... 50

4.4.3 Use of Unskilled Workers......................................................................... 51

4.4.4 Importing Workers ............................................................................... 52

4.5 Conclusion and Future Works................................................................... 54

5. Worker Health and Safety during Post-Disaster Reconstruction: A pilot study ....... 56

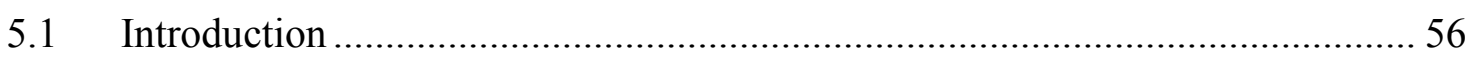

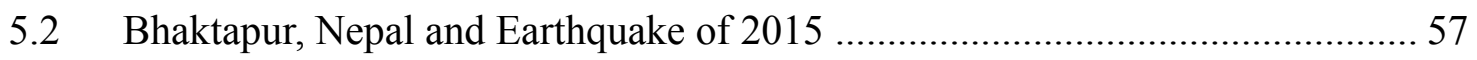

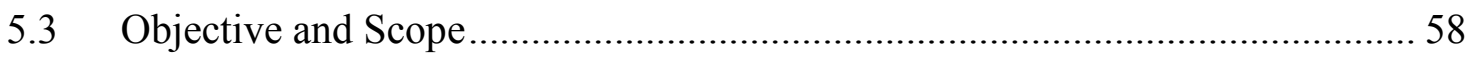

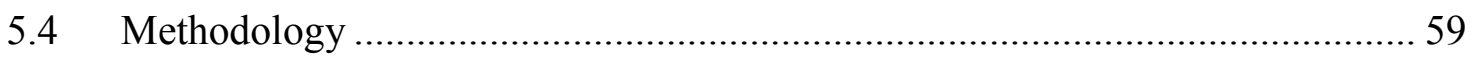

5.5 Issues Pertaining to the Health and Safety of the Construction Workers ........... 61

5.5.1 Differences between Regular Construction and PDR .................................. 61

5.5.2 Use of Personal Protective Equipment (PPE) …………………………...... 62

5.5.3 Involvement of Immigrant Workers ……………………………………...... 64

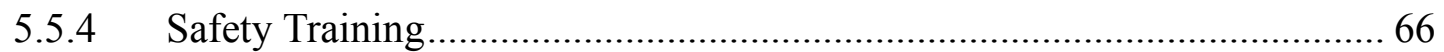

5.5.5 Safety concerns before and after the earthquake ...................................... 67

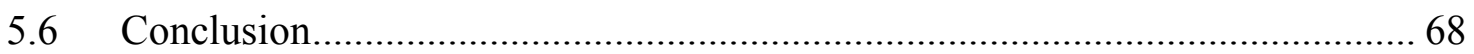

6 Worker Health and Safety during Post-Disaster Reconstruction: In depth Analysis 71

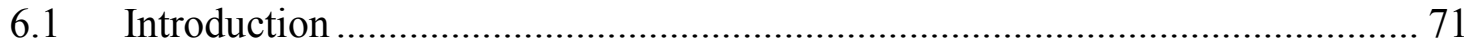

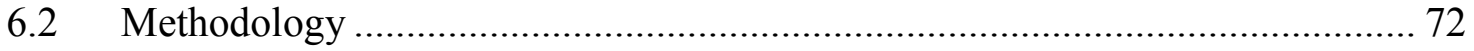

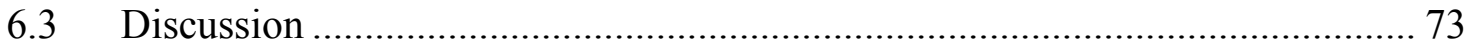

6.3.1 Use of Unskilled Workers ..................................................................... 73

6.3.2 Mental Health of Workers ……………………................................... 76

6.3.3 High Inflow of Money ………………………….................................... 79

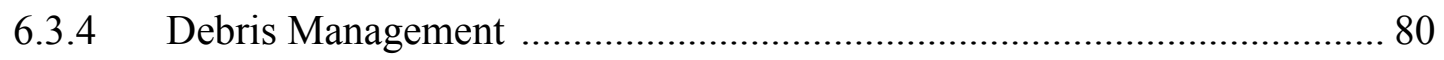

6.3.5 Chemical Contamination and Health Issues ……………………….......... 82

6.3.6 Participation of Community People ......................................................... 83

6.3.7 Building Back Faster Syndrome ........................................................... 86

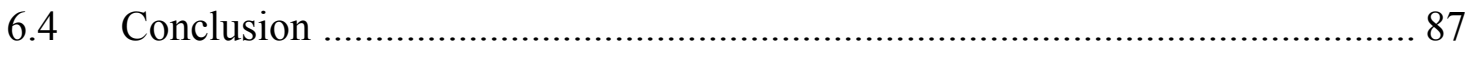

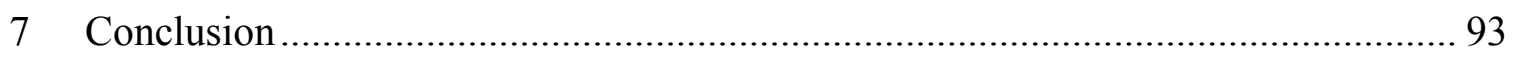

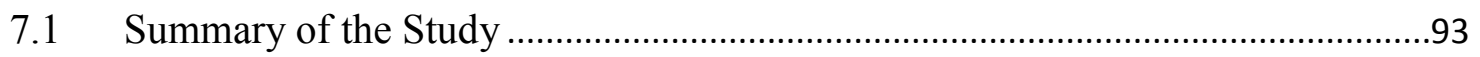

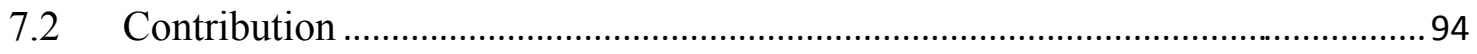

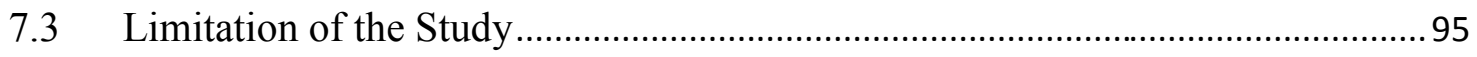




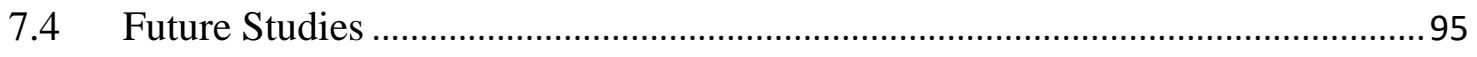

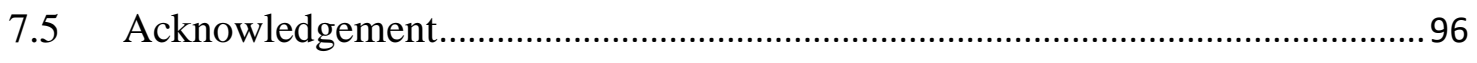

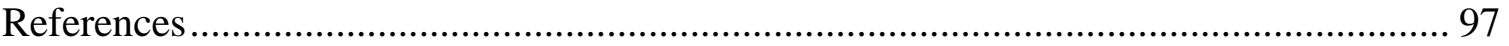




\section{LIST OF TABLES}

TABLE

PAGE

Table 1: Death Toll by Disaster Type from 2000-2018 (UNISDR) …………………...... 13

Table 2: Recent Natural Disasters and their Impact ………………………………... 15

Table 3: Activities of Post Disaster Reconstruction (PDR) Phase [Adapted and Modified from Lindell.201.7]........................................................................................ 17

Table 4: Number of workplace deaths in US, 2017 (OSHA, 2017) ................................ 24

Table 5: Factors Retrieved from the Literature ............................................................ 26

Table 6: List of Participants from Nepal...................................................................... 35

Table 7: Number of Publication from 2000-2018(Adapted and Modified from (Yi \&

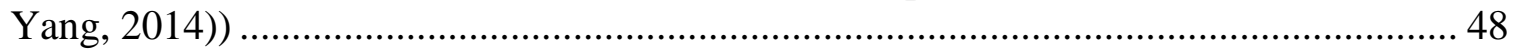

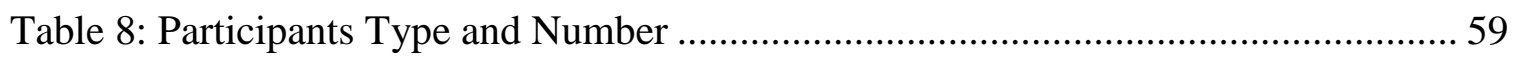

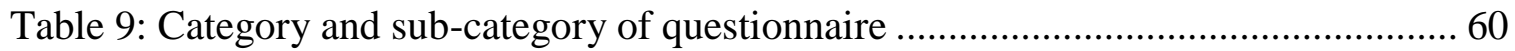

Table 10: Participants Type and Number for Further Investigation ................................ 72 


\section{LIST OF FIGURES}

FIGURE

PAGE

Figure 1: Increasing Trend of Disasters over the Years .......................................... 14

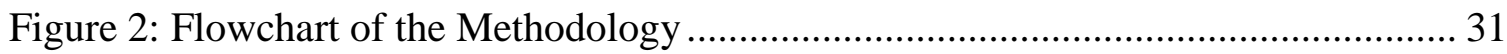

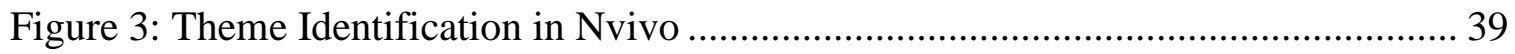

Figure 4: Nodes and Frequency of Publications in Nvivo ........................................... 40

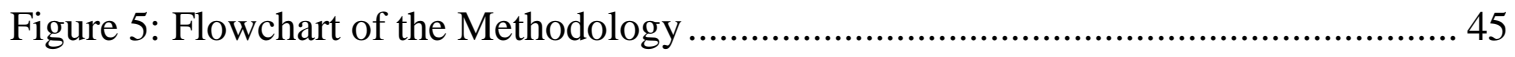

Figure 6: Activities of Post Disaster Reconstruction (PDR) Phase ............................... 46

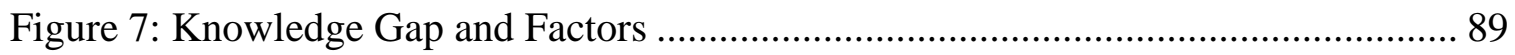




\section{CHAPTER 1}

\section{Introduction}

\subsection{Disasters and their Impact}

The term disaster has increasingly become part of everyday vocabulary as the number of disaster events being reported continues to rise at an unimaginable rate. The study of disasters and their impacts on communities has gained prominence in current society as a result. Disasters have been defined and described in a number of different ways by key organizations operating in the disaster management sector. The United Nations Officer for Disaster Risk Reduction (UNISDR) [1] defines disasters as follows:

"A serious disruption of the functioning of a community or a society involving widespread human, material, economic or environmental losses and impacts, which exceeds the ability of the affected community or society to cope using its own resources."

The Centre for Research on the Epidemiology of Disasters (CRED) [2] on the other hand defines the terminology as

"An unforeseen and often sudden event that causes great damage, destruction and human suffering” or, "a situation or event which overwhelms local capacity."

And U.S. Geological Survey [3] defines it as

"A naturally occurring or man-made geological condition or phenomenon that presents a risk or is a potential danger to life or property." 
Usually, there are two types of disasters: natural and man-made disasters. According to the Cambridge Dictionary, natural disasters are those "Natural events such as floods, earthquakes, or tsunamis that kill or injure a lot of people." However, natural disasters do not only affect human life but also the economy of the country and social aspects as well. On the other hand, man-made disasters are those disruptive events that are caused by human intent, negligence, or error; or involving a failure of a man-made system. Both types of disasters cause significant losses to the life and property of a country and society.

Natural disasters are on the exponential rise over the years, and the number of lives lost due to natural disasters is very significant. In 2018 alone, 12,751 number of people lost their lives due to natural disasters. And from 2000 to 2017, 77,145 number of people lost their lives [4] (Table 1). The year 2018 consumes almost $25 \%$ of the total number of the affected people from 2000 to 2018 which signifies the fact that the number of natural disasters and loss due to the disasters is on the rise.

Table 1: Death Toll by Disaster Type from 2000-2018 (UNISDR)

\begin{tabular}{lcr}
\hline Event & Annual Average (2000-2017) & 2018 \\
\hline Drought & 1,361 & 0 \\
\hline Earthquake & 46,173 & 4,321 \\
\hline Extreme Temperature & 10,414 & 536 \\
\hline Flood & 5,424 & 2,859 \\
\hline Landslide & 929 & 282 \\
\hline Mass Movement (dry) & 20 & 17 \\
\hline Storm & 12,722 & 878 \\
\hline Volcanic Activity & 31 & \\
\hline
\end{tabular}




\begin{tabular}{lrr}
\hline Wildfire & 71 & 247 \\
\hline Total & $\mathbf{7 7 , 1 4 5}$ & $\mathbf{1 2 , 7 5 1}$
\end{tabular}

The following figure 1 shows how significantly the number of natural disasters has increased over time. And it is also worthwhile to note that these are the only reported disasters. There might be a lot of other natural disasters that are not even reported to the correct authority.

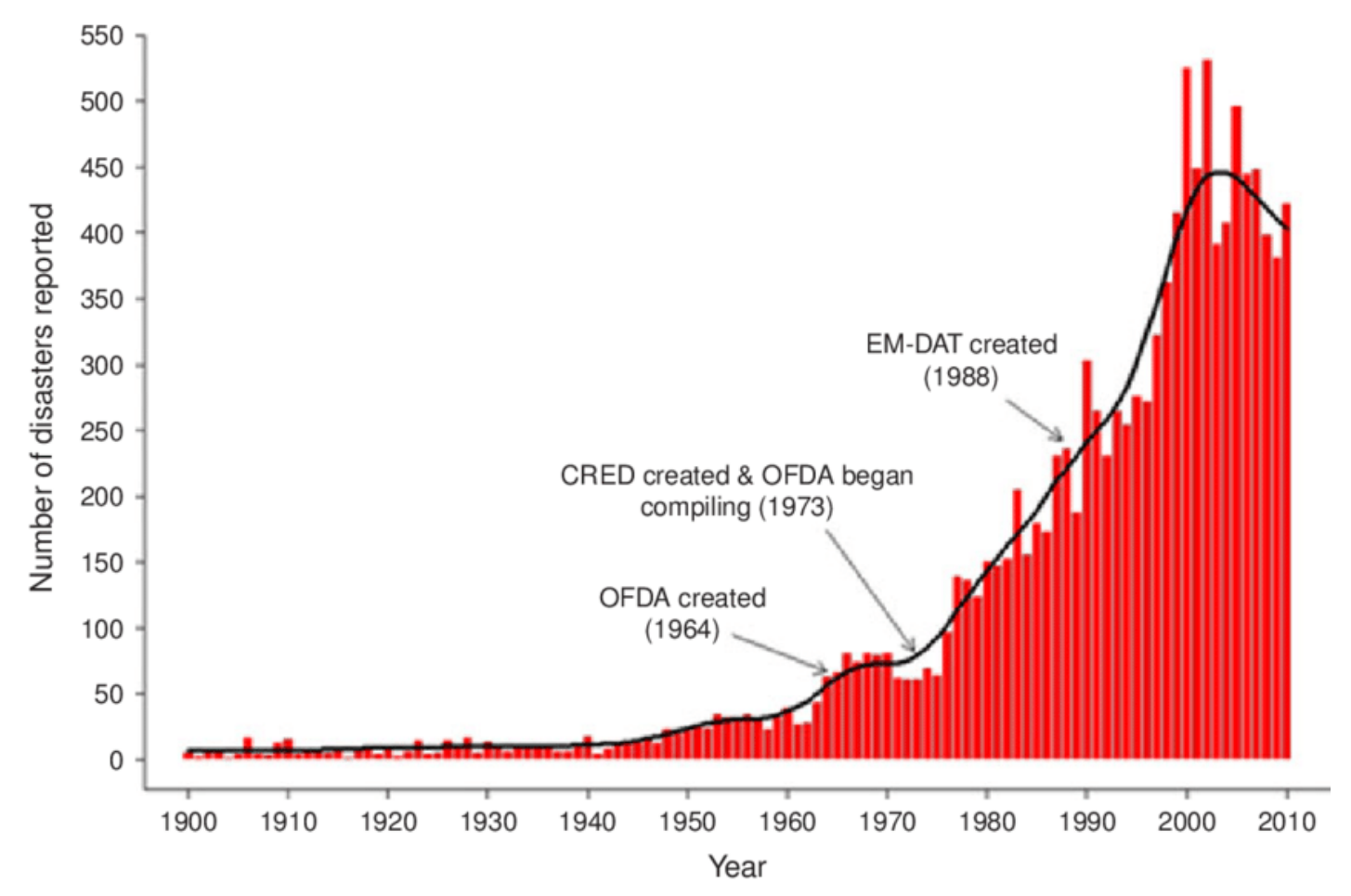

Figure 1: Increasing Trend of Disasters over the Years

The statistics from EM-DAT show that from 1974 to 2003, 86\% of disaster- related deaths were due to natural disasters proving natural disasters to be a major concern for 
communities [4]. Table 2 below shows details of some of the world's biggest disasters and their damage statistics.

Table 2: Recent Natural Disasters and their Impact

\begin{tabular}{lccll}
\hline Name & Year & Death & $\begin{array}{l}\text { Economic } \\
\text { Loss }\end{array}$ & Source \\
\hline $\begin{array}{l}\text { Hurricane Katrina, } \\
\text { U.S. }\end{array}$ & 2005 & 1,836 & $\$ 81$ Billion & $\begin{array}{l}\text { National Oceanic and } \\
\text { Atmospheric Administration } \\
\text { (NOAA) }\end{array}$ \\
\hline $\begin{array}{l}\text { Sichuan } \\
\text { Earthquake, China }\end{array}$ & 2008 & 70,000 & $\$ 29$ Billion & World Bank \\
\hline $\begin{array}{l}\text { Haiti Earthquake } \\
\text { Earthquake and }\end{array}$ & 2010 & 250,000 & $\$ 14$ Billion & $\begin{array}{l}\text { Inter-American Development } \\
\text { Bank }\end{array}$ \\
\hline $\begin{array}{l}\text { tsunami, Japan } \\
\text { Nepal Earthquake }\end{array}$ & 2015 & 9,000 & $\$ 235$ Billion & World Bank \\
\hline
\end{tabular}

Guha- Sapir et al. (2004), and Wisner et al. (2004) identified vulnerability being a key contributor to disasters [5], [6], the increasing number of disasters arising from natural phenomena may be attributed to the increasing vulnerabilities of communities. This is due to the result of poorly planned human settlements and environmental degradation. The vulnerability can arise due to geographical, social and/or economic conditions. Common types of vulnerabilities which increase disaster risk include [7]:

1. Physical, i.e., exposure of populations to potential hazards such as living in flood plains or seismically active areas

2. Social, i.e., factors such as population growth, conflicts, and societal discrimination 
3. Economic, as a result of the diversities in a country's economy, availability of insurance and loans, financial assets and debts, and access to basic infrastructure.

4. Environmental, i.e., soil degradation, erosion, deforestation, chemical/biological pollution and availability of water

\subsection{Recovery from the Natural Disasters}

Recovery from the impact of the disaster has several phases and stages comprising of multiple activities to be done within the phases. Response and Recovery are the two main stage that takes place after a disaster [8]. Within these two stages, there are several phases and activities. According to Lindell (2017), disaster recovery has four stages, e.g. Disaster Assessment, Short Term Recovery, Long-term Reconstruction and Recovery Management [9]. Another popular theory regarding disaster recovery phases states that the recovery after a disaster goes through four phases, e.g. Emergency Action, Recovery of Basic Services, Replacement Reconstruction and Developmental Reconstruction [10]. Haas et al. (1977) broke down the activities following a disaster (i.e., response phase and recovery phase) into four periods:

1. The Emergency Period - the initial period following a disaster, usually ranging from a few hours to a few days. Normal community functions are disrupted, and beginnings of the clean-up are initiated.

2. Restoration Period - the period where major services, communication, and transportation are restored. This period can take from several weeks to a few months. 
3. Replacement Reconstruction Period - the built environment is restored to predisaster levels, and social and economic activities are returned to pre-disaster levels or higher.

4. Commemorative, Betterment and Developmental Reconstruction Period - a period where memorials and commemoration take place, as well as major construction activities to improve the city for future growth and development.

\subsection{Post Disaster Reconstruction (PDR)}

Post Disaster Reconstruction (PDR) has been relatively a new topic of research for scholars in recent years. It has been seen that the scholars started focusing on Post Disaster Reconstruction issues as research topic from the early 2000s and there is a significant growth in the research topic after 2011 [11]. Considering the definitions and information extracted from the literature, it can be said that Post Disaster Reconstruction (PDR) is a phase that comprises of several activities that are related to construction and that are performed after the disaster. PDR phase may work independently or simultaneously with other phases after a disaster. In general, debris management, construction, retrofitting, and demolition activities fall under the phase of PDR. Table 3 represents a summary of Phases and Activities after disaster thus defining PDR and its activities.

After the initial post-disaster response activities during the emergency and restoration periods, it is important to move quickly to the reconstruction and long-term recovery phase in order to restore a sense of normalcy in affected communities as soon as possible. Despite the increasing number of post-disaster reconstruction experiences encountered, this phase still remains inefficient and poorly managed in terms of health and safety [12], [13]. The post disaster reconstruction period needs to be further studied and improved. 
Traditionally, post-disaster reconstruction consisted of simply repairing the physical damage that has been induced by a disaster. However, some other studies have pointed out that rebuilding the built environment and infrastructure exactly as they were prior to a disaster often re-creates the same vulnerabilities that existed earlier [14], [15].

Table 3: Activities of Post Disaster Reconstruction (PDR) Phase [Adapted and Modified from Lindell 2017]

\begin{tabular}{|c|c|c|c|}
\hline \multirow{11}{*}{ Response } & \multirow{5}{*}{ Disaster Assessment } & Rapid Assessment & \multirow{28}{*}{ Post Disaster Reconstruction } \\
\hline & & Preliminary Damage Assessment & \\
\hline & & Site Assessment & \\
\hline & & Victims' Need Assessment & \\
\hline & & Leassons Learned & \\
\hline & \multirow{6}{*}{ Short Term Recovery } & Impact Area Secured & \\
\hline & & Temoporary Shelter & \\
\hline & & Infrastructure Restoration & \\
\hline & & Debris Management & \\
\hline & & Emergency Demolition & \\
\hline & & Repair & \\
\hline \multirow{17}{*}{ Recovery } & \multirow{9}{*}{ Long Term Recovery } & Hazard Source Control & \\
\hline & & Land Use Practices & \\
\hline & & Building Construction Practices & \\
\hline & & Public Health/Mental Health & \\
\hline & & Infrastructure Resilience & \\
\hline & & Economic Development & \\
\hline & & Historic Preservation & \\
\hline & & Environmental Recovery & \\
\hline & & Disaster memorialization & \\
\hline & \multirow{8}{*}{ Recovery Management } & Agency Notification and Mobilization & \\
\hline & & Mobilization of Recovery Facilities & \\
\hline & & Internal Director and Control & \\
\hline & & External Coordination & \\
\hline & & Public Information & \\
\hline & & Recovery Legal Authority & \\
\hline & & Administrative and Logistical Support & \\
\hline & & Documentation & \\
\hline
\end{tabular}

\subsection{Problem Statement}

The recovery period following a disaster poses an opportunity to address and rectify vulnerability issues found in communities [16] specially in people that are involved in reconstruction activities. One of such issues is the Construction Workers' Health and Safety during the Post Disaster Reconstruction (PDR) Phase. Many literatures identified that this one issue had been significantly neglected throughout the era of PDR research. 
Construction Workers Health and Safety is a well-studied subject for the last few decades. But no significant study has been done till now to identify how disasters impact the construction workers' health and safety in a disaster affected area during the post disaster reconstruction phase. It is thus important to identify the significance of disasters on the construction workers' health and safety.

\subsection{Objectives of the Study}

This thesis has three main objectives, and they are as follows:

1) To identify a knowledge gap in the literature of construction workers' health and safety during post disaster reconstruction phase.

2) To identify the similarities and dissimilarities between regular construction and PDR in terms of construction workers' health and safety.

3) To identify the unique factors affecting the health and safety of construction workers at PDR.

\subsection{Scope}

This study is based on extensive literature review and a set of secondary data containing in depth semi structured interviews. This study has been done with the context of Nepal Earthquake 2015. These data represent the views of a few individuals at a specific time and place. Limited qualitative data are not usually generalizable to larger populations; however, knowledge and lessons can be transferred to other contexts for further study. This study is only limited to identifying the knowledge gap in the literature and finding out factors affecting health and safety of construction workers through in depth interviews. 


\subsection{Structure of the Thesis}

This section describes the chapters of this thesis. Two of the chapters are extracted from two accepted conference papers, and one chapter is extracted from the manuscript to be submitted for journal publication. Rest of the chapters are written to provide a contextual framework to the thesis.

Chapter 1 provides the introduction and background of this study. It gives an overview of the disasters, recovery and post disaster reconstruction. This chapter also includes problem statement, objective and scope of the study.

Chapter 2 talks about the previous works that have been done on the context of post disaster reconstruction. This chapter reveals the initial literature review that has been to develop the concepts of post disaster reconstruction and related contexts. This findings of this chapter inspired the author to conduct the literature review systematically thus finding a gap in knowledge.

Chapter 3 provides an overview of the methodology of the whole study. It states the research questions that were posed after the initial background study (chapter 2) and describes the systematic literature review process. It also talks about the questionnaire formulation, process of data collection from a secondary source and data analysis methods.

Chapter 4 covers the systematic literature review in detail. This chapter provides the definition of post disaster reconstruction generated for this study. It identifies a knowledge gap in the literature though a systematic review process and also points out factors that

affect construction workers health and safety during post disaster reconstruction. This chapter is based on Uddin, SMJ., Pradhananga, N. (2019), "Construction Workers Health 
and Safety at Post-Disaster Reconstruction (PDR) Phase: A Knowledge Gap Analysis" 55th ASC Annual International Conference Proceedings (2019) (Accepted).

Chapter 5 presents a pilot study conducted following the systematic literature review. A set of qualitative data was collected from a secondary source. The set of data contains semi structured interviews conducted in Bhaktapur Nepal. The analysis of the interviews represent the issues pertaining to the health and safety of the construction workers during post disaster reconstruction. This chapter signifies the differences between regular construction and PDR and also talks about issues such as the use of personal protective equipment, the involvement of immigrant workers and safety training. This chapter is based on Uddin, SMJ., Prajapati, J., Pradhananga, N. (2019). “Worker Health and Safety during Post-Disaster Reconstruction: A case study in Bhaktapur" 2nd International Conference on Earthquake Engineering and Post Disaster Reconstruction Planning (ICEE-PDRP 2019) (Accepted).

Chapter 6 investigates even further based on the pilot study done in chapter 5. All the data that have been analyzed in this chapter were collected from a secondary source. This data set contains qualitative data collected through in depth semi structured interviews. This chapter explores more factors (unique to chapter 5) that affect the health and safety of the construction workers during PDR. This chapter is extracted from the manuscript of a paper to be submitted for journal publication.

Finally, chapter 7 concludes the study by presenting the summary, contribution, limitation, and possible future studies. 


\section{CHAPTER 2}

\section{Background of the Study}

\subsection{Previous Works Related to Post Disaster Reconstruction (PDR)}

The occurrence of natural hazards is inevitable. It is reported that at least 250 natural disasters take place every year around the world and it is evident that the number of natural disasters is increasing every year [17]. However, a UN report states that from 1995 to 2015, there have been over 6,457 natural disasters have taken place. In this 20 years of span 606,000 lives have been lost reportedly, 4.1 billions of people injured and left homeless and the economic loss due to infrastructure damage is estimated to be over US\$1.8 trillion [1]. In the coming years, the frequency and magnitude of disasters are expected to increase due to the climate change [18], and the impact on physical properties is going to be extreme nevertheless [19]. Natural Disasters affect human life in several ways including loss of lives, economic damage and infrastructure damages. Addressing it from a different point of view, post disaster phase opens a window of opportunity to address issues that might not have been addressed otherwise, e.g. poor infrastructure, disasters risks, vulnerable structures and many more [20]. Recovery from the impact of the disaster has several phases and stages comprising of multiple activities to be done within the phases. Response and Recovery are the two main stage that takes place after a disaster [8]. Within these two stages, there are several phases and activities. According to Lindell (2017), disaster recovery has four stages, e.g. Disaster Assessment, Short Term Recovery, Long-term Reconstruction and Recovery Management. Another popular theory regarding disaster recovery phases states that the recovery after a disaster goes through four phases, e.g. Emergency Action, Recovery of Basic Services, Replacement Reconstruction and 
Developmental Reconstruction [10]. However, Post Disaster Reconstruction (PDR) has been relatively a new topic of research for scholars in recent years. It has been seen that the scholars started focusing on Post Disaster Reconstruction issues as research topic from the early 2000s and there is a significant growth in the research topic after 2011 [11]. Considering the definitions and information extracted from the literature, we believe that Post Disaster Reconstruction is a phase that comprises of several activities that are performed after the disaster. PDR phase may work independently or simultaneously with other phases after a disaster. In general, debris management, construction, retrofitting, and demolition activities fall under the phase of PDR.

The construction industry is one of the most dangerous industries in terms of health and safety due to its own dynamic nature [21]. Construction activities pose a great challenge to the health and safety of the workers. Among the other industries, e.g., agriculture, manufacturing, transportation, etc. construction ranks in one of the top three in terms of fatality. Many literatures have already stated and agreed that construction industry has one of the highest fatality rates in the world [14], [22] while reconstruction during post disaster period makes it more vulnerable and prone to construction hazards [23], [24]. From 2003 to 2017 more than 14,729 workers have died on the construction industry averaging more than 960 deaths per year and 5,190 fatal work injuries occurred in the US in 2016 which was a 7\% increase from 2015 [25]. In 2017 only, 971 people died in the construction workplace thus making the construction industry having the most fatality in the year. Table 4 shows the deaths from different industries in the year of 2017. 
Table 4: Number of workplace deaths in the US, 2017 (OSHA, 2017)

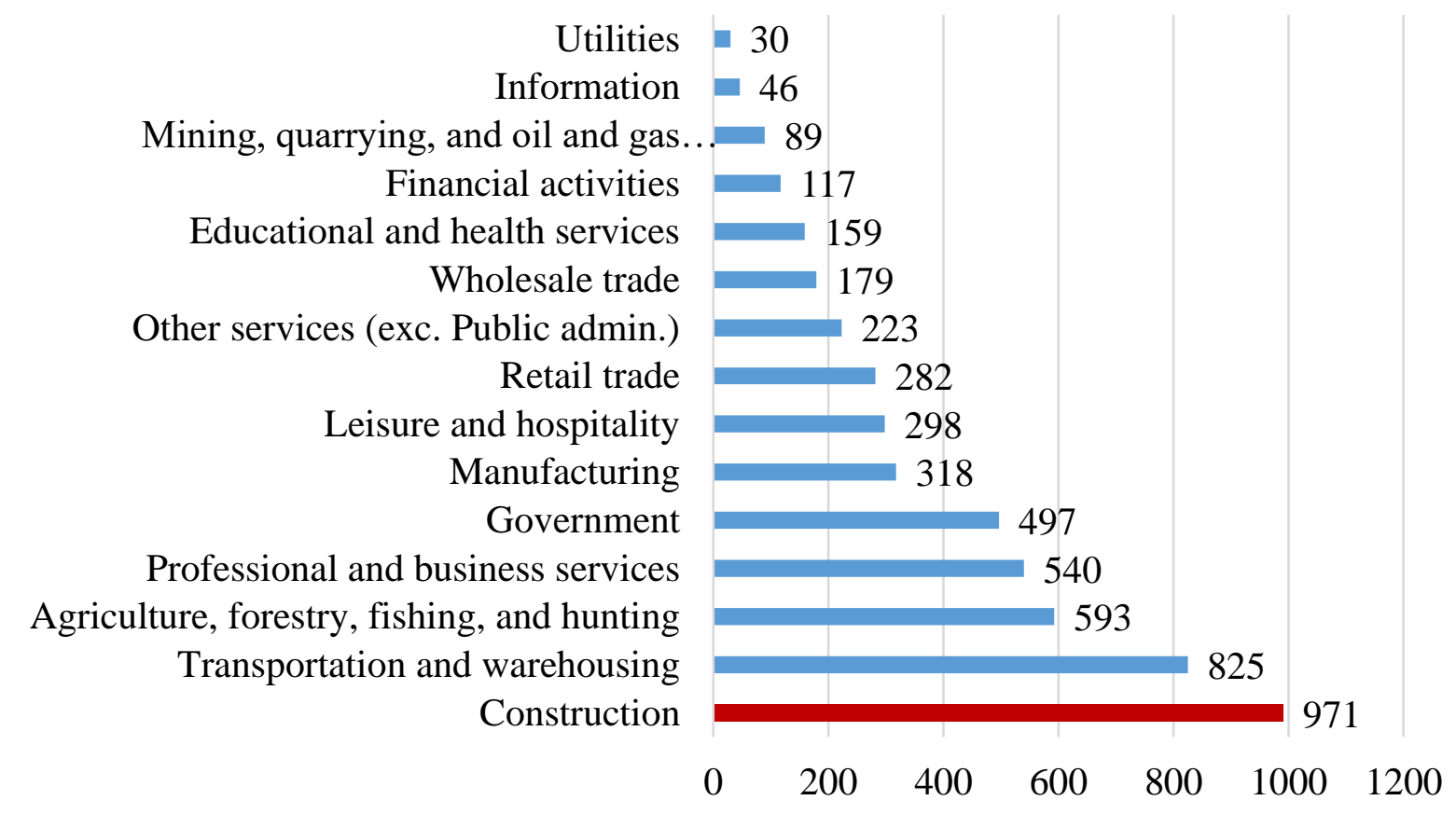

Private industry employers also reported about 2.9 million non-fatal workplace injuries and illnesses. Among those, 991 fatal and 203.5 thousand non-fatal workplace injuries and illness were also reported in the private construction sector. People are dying at construction sites almost at a constant and alarming rate. Deaths may be inevitable in some cases but the fatality rate at construction sites can be monitored, and measures can be taken. On that regard, scholars have been trying to identify and classify the factors that affect the health and safety of construction workers. OSHA (Occupational Safety and Health Administration) has identified falls, struck by an object, electrocution, and caughtin/between as cause of majority of fatalities, $63.7 \%$ deaths in 2016, in private construction sector [26]. Many of the scholars have identified the general factors and causes that affect the health and safety of construction workers. According to Umar el.al (2018), the main four causes of construction fatalities in Oman are 'equipment/materials', 'workers', 
'environment' and 'management' [27]. In another similar case study conducted in Oman, Al-Khaburi et.al. (2018) stated that the five major causes that lead to construction accidents are 'poor instruction by the supervisor', 'lack of training', 'lack of workers' awareness', 'lack of maintenance of equipment' and 'underestimating dangers by workers'. Following a review paper on accident casual factors on the building construction sites, the top ten most mentioned factors affecting health and safety of construction workers are 'lack of personal protective equipment (PPE)' 'defective or poor unsafe equipment' 'lack of training' 'poor safety consciousness of workers or managers' 'unsafe method of handling materials or equipment during operations' 'lack of experienced project managers or workers' 'fatigue by workers because of overwork' 'unsafe condition of workplace' 'reluctance to incest or lack of concern for safety by management' ' ineffective operations or lack of compliance to safety regulations' 'insufficient or lack of housekeeping program' [28]. There are various causes of construction accidents that affect the health and safety of construction workers and scholars have been addressing them in an extensive way.

As stated earlier, Post Disaster Reconstruction is a relatively new topic of research among scholars. Concrete definition, scope, and activities are yet to be defined for PDR. However, many scholars agree that Post Disaster Reconstruction is a complex issue to be addressed and it has its several aspects and dimensions [29]. PDR projects are one of the most challenging tasks to do since PDR projects come along with uncertainties and complexity, more than regular construction [30], [31]. In spite of having more uncertainties and complexity than regular construction, a little difference was observed between these two by Masurier et al. (2006) since same stakeholders are involved in both regular and 
reconstruction projects [8]. However, a PDR project should address the existing tools and measures and may need to adapt to new ones due to its own uniqueness [11], [32].

A study on the research trends of post disaster reconstruction identified the key issues scholars have been dealing with from the early 2000s to 2012. Most of the research papers of PDR are on stakeholder analysis and reconstruction approach. the other major issues are sustainable reconstruction, resource allocation, pre-disaster preparations, delivery and assessment of resilience and vulnerability, waste processing, reconstruction policy and structure of governance [33].

After reviewing the previous publications of Post Disaster Reconstruction (PDR), the author of this study has identified several factors that contribute significantly to the safety of construction workers at PDR sites (table 5). However, none of the previous studies have investigated the construction workers' health and safety during post disaster reconstruction. Scholars seemed to be mentioning some of the issues related to health and safety, but no significant focus has been given. Those factors lead to some specific outcomes thus ultimately affecting constructions workers' safety. The factors affecting the health and safety of the construction workers' health and safety during post disaster reconstruction phase that have been identified from the literature are listed in the table below:

Table 5: Factors Retrieved from the Literature

\begin{tabular}{ll}
\hline $\begin{array}{l}\text { Factors Affecting Construction Workers } \\
\text { Health and Safety during PDR }\end{array}$ & Literature Mentioning the Factors \\
\hline Use of Unskilled Workers & {$[14],[22],[34]$} \\
\hline Importing Workers & {$[14]$} \\
\hline High Inflow of Money & {$[14],[35]-[37][15],[38][38]$} \\
\hline
\end{tabular}




\begin{tabular}{ll}
\hline $\begin{array}{l}\text { Factors Affecting Construction Workers } \\
\text { Health and Safety during PDR }\end{array}$ & Literature Mentioning the Factors \\
\hline Insufficient Safety Equipment & {$[38]$} \\
\hline Alien Language & {$[38]$} \\
\hline Chemical Contaminants & {$[14],[39],[40]$} \\
\hline Lack of Training & {$[23],[38],[41][42]$} \\
\hline Hazardous Debris & {$[39],[40][43]$} \\
\hline Building Back Faster Syndrome & {$[14],[35],[37][22]$} \\
\hline Post-Traumatic Stress Disorder & {$[44],[45]$} \\
\hline
\end{tabular}

The construction industry is itself a unique phenomenon and one of the most hazardous industries around the world [24], [40], [46], [47]. And it is evident that PDR sites are more hazardous to construction workers and they are more exposed to construction accidents due to the nature of the PDR sites. The presence of hazardous debris itself makes the construction site more vulnerable in terms of safety (Kennedy et al., 2008; Grosskopf, 2010). A 2008 study stated that most of the disaster related injuries happen to construction workers during the post disaster reconstruction process and they are prone to all the construction hazards similar to routine construction hazards but with even more exposure [39]. [43] reports that increasing injury trends, identified illness cluster, and unconfirmed illnesses have been observed among the workers involved in post disaster reconstruction which proves that Construction Workers at PDR sites are not only vulnerable to construction hazards, but they are also exposed to illnesses, both identified and unidentified. Along with physical illnesses, reconstruction workers have also been identified as having mental illness during the reconstruction period. Most of the reconstruction workers are also disaster survivors as well. Reconstruction workers were found to be suffering from Post-Traumatic Stress Disorder (PTSD) and Depression which often led them to suicidal attempts [44]. 
There are more elements that contribute to the vulnerability of PDR sites for Construction workers other than the hazards for routine construction sites. After a major natural disaster and heavy loss of infrastructures, the main focus moves to the faster rebuilding and shifting the affected people to their shelters. On top of that, a high inflow of funds for the reconstruction projects take place which urges the government and construction companies to build as many structures as early as possible [48], [49]. Because of that, they compromise with the construction workers' skills and expertise. With less skilled work force, they became more exposed to construction hazards. This scenario has been observed after the tsunami in Aceh and Sri-Lanka 2004, [14], [35] Nepal Earthquake 2015 [50] [51] and Haiti Earthquake 2010 [52], [53].

It has also been observed through a literature review that after natural disasters, there is generally a huge lack of construction workers. It has been seen on many occasions that due to lack of workers, community people start building their own houses. According to CPSC, community people get injured or even die while doing their regular chores. Only in 2012, more than 15,000 people got injured during the holiday season while decorating their own home [54]. While people are getting injured doing regular household works, it is quite evident that their involvement in PDR works is not without certain risks. The involvement of community people is always risky since most of them don't usually possess any construction skills or experience [55].

However, to meet the need of workers at PDR sites, additional workers are needed, and workers are imported from nearby countries [8], [14]. The imported workers are reported to be "skimped" in terms of wages, safety materials and working time [15]. After the 
hurricane Katrina, it was observed that most of the construction workers for reconstruction works were immigrants, even without any documents. It has been reported that those workers were exploited by their employers thus exposing them to more construction hazards by not providing enough safety training and safety equipment. On top of that, because of being foreigners they had difficulty understanding the language, safety signs and communicating at PDR sites [38]. 


\section{CHAPTER 03}

\section{Methodology}

\subsection{Research Question}

The motivation for this study is to investigate and find out the knowledge gap in the concept of post disaster reconstruction (PDR), its significance, differences between regular construction and PDR and finally factors affecting the health and safety of the construction workers with the context of Nepal earthquake 2015.

Therefore, the research questions were set to be as following:

1) What are the themes in the field of Post Disaster Reconstruction (PDR) that have been studied so far?

2) How important is studying construction workers' health and safety during post disaster reconstruction?

3) What are the factors that affect construction workers' health and safety during post disaster reconstruction and if they are any different to the regular construction?

\subsection{Systematic Literature Review}

To find out a study gap in the field of Post Disaster Reconstruction, a systematic, rigorous literature review has been done. According to [56], the definition of a systematic literature review is as following:

"A systematic review attempts to collate all relevant evidence that fit pre-specified eligibility criteria to answer a specific research question. It uses explicit, systematic methods to minimize bias in the identification, selection, synthesis, and summary of studies. " 
Researchers [33], [57], [58] have been identified to adopt the methodology to carry out extensive literature reviews in the past as well. A systematic literature review gives a good understanding of the background of the study and researches that have been carried out so far within the boundary of the objective of the study. To conduct the literature review, a set of research questions were set. Figure 2 below shows the flowchart of the methodology adapted for the systematic literature review.

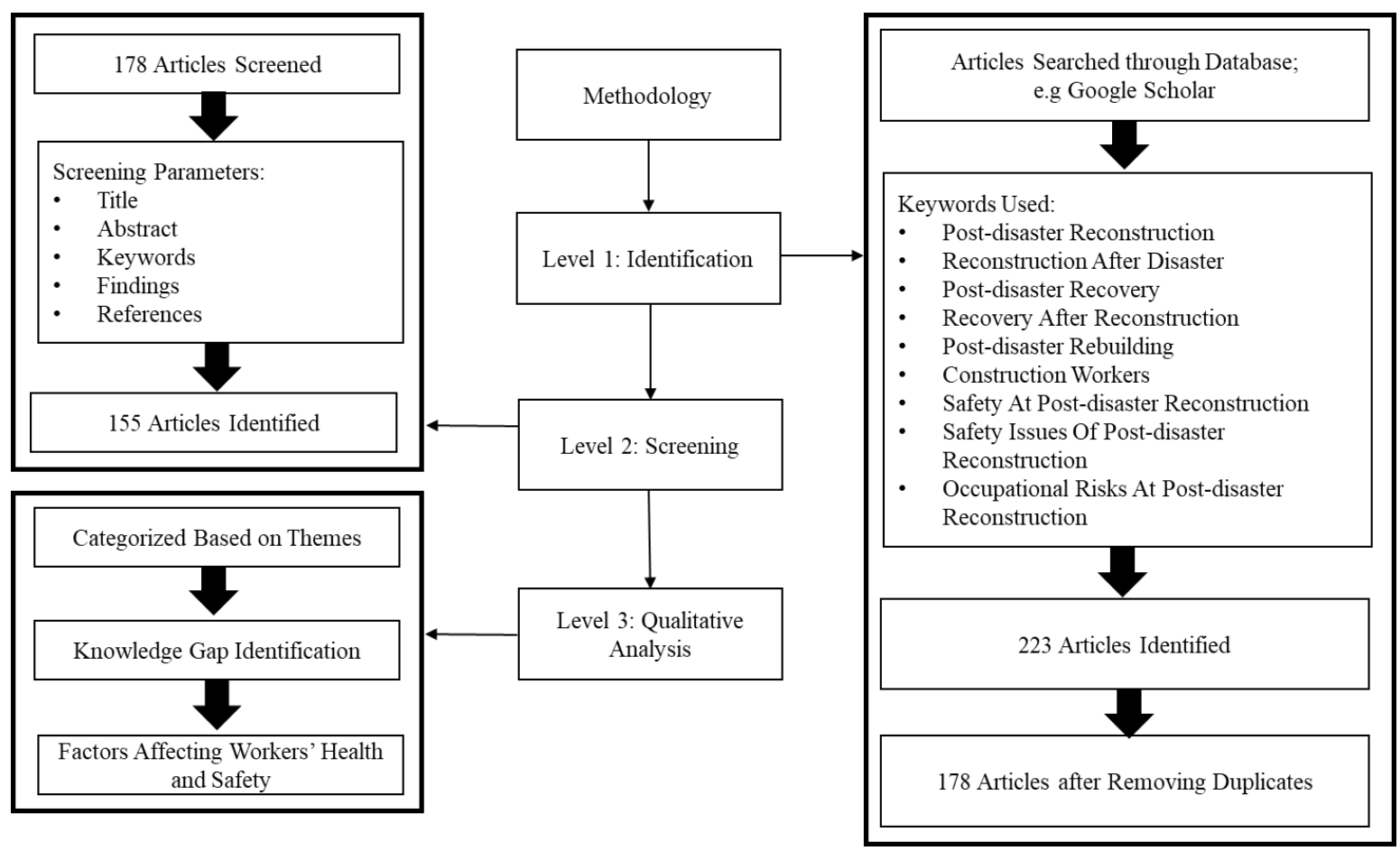

Figure 2: Flowchart of the Systematic Literature Review

This systematic literature review has been conducted in three levels. Level 1 is the process of identifying related scholarly articles. Level 2 is the screening process of those articles thus finalizing articles for study and analysis. And Level 3 is the qualitative analysis of the retrieved data from Level 1 and Level 2. 


\subsubsection{Level 1: Identification of Target Articles}

To address research questions, literature has been searched using Google Scholar since google scholar is a practical point to start any literature review from scratch [59]. To initiate the search, some specific keywords were identified from the literature and used. The keywords are as follows:

"post disaster reconstruction", "reconstruction after disaster", "post disaster recovery", "recovery after reconstruction", "post disaster rebuilding", "construction workers", "safety at post disaster reconstruction", "safety issues of post disaster reconstruction", "and occupational risks at post disaster reconstruction”.

Each of these keywords was used one at a time to look for the articles that came up as the search results. For each keyword, the first 50 search results were examined to identify papers related to the keyword. Among the search results, 223 papers were extracted and later 178 papers were finalized upon removing the duplicates from the pool of articles.

\subsubsection{Level 2: Screening of the Target Articles}

Level 2 is about screening the articles using multiple parameters. Search scope was narrowed down by examining the Title, Abstract, Keywords, Findings, and References of the research papers to identify the articles that are related to the scope of this study. Finally, 155 research papers were selected to be studied. On the process of doing that, papers were categorized by their theme within the scope of PDR using the software NVIVO. A total of 14 themes were identified. 


\subsubsection{Level 3: Qualitative Analysis}

The third level comprises of all the analysis that has been done using those 155 selected articles. Firstly, the articles were categorized based on their research themes. As specified earlier, a total of 14 themes were identified following the process. After that, a knowledge gap has been identified among the literature of post disaster reconstruction. And further, the factors affecting construction workers' health and safety during the PDR phase have been identified.

\subsection{Data Collection}

Secondary data is a powerful tool for providing context to an otherwise small-scale study, as well as being an efficient way of bringing together a large amount of data, particularly where access to the field may be difficult [60]. Since Nepal has been taken as a case to study for this research, access to the field had been difficult due to limited resources and time constraints. All the data that have been used in this study are collected from secondary sources. Data have been collected from the Department of Civil Engineering, Khwopa Engineering College in Nepal. One of the professors from the college, Mr. Jeetendra Prajapati and his students, interviewed 38 individuals following a semi-structured questionnaire in two steps. The first set of data has been used by the author to conduct a pilot study and the second set of data has been utilized for further analysis of this research. Following sections describe the process of questionnaire formulation and interviews, which was adapted by the interviewees. Author of this thesis had a limited amount of input in the questionnaire development; however, all the interviews were conducted solely by the professor and students of Khwopa Engineering College, Nepal. 


\subsubsection{Questionnaire Formulation}

Interviewing is one of the most common methods used in small-scale and exploratory research. And semi-structured interviews are more effective when there is no prior data or concept available on the proposed topic. In the semi-structured questionnaire interview, the interviewer sets up a general structure by deciding in advance the ground to be covered and the main questions to be asked. The detailed structure is left to be worked out during the interview, and the person being interviewed has a fair degree of freedom in what to talk about, how much to say, and how to express it. Semi-structured interviewing is a very flexible technique for small-scale research. It is not suitable for studies involving large numbers of people. [61]

An extensive literature review of existing research and books on post disaster reconstruction and semi-structured interview procedure was done by the interviewers with a view to coming up with the information used in the interview questionnaires. This semistructured questionnaire was divided into two sections. One section comprises of open ended questions with multiple follow up questions, and the other section comprises of close ended questions. Open ended questions healed dealing with the main research questions of this study. And the close ended section healed dealing with the demographic information of the respondents.

\subsubsection{Process of Conducting Interviews}

Following the formulated semi-structured questionnaire, the interviewers collected qualitative data from the area of Bhaktapur Nepal which is one of the most affected areas by the Nepal earthquake 2015. A total of 38 respondents were interviewed from different 
stakeholders. The interviews were done in two stages. Firstly, a small scale questionnaire interview was conducted with 14 respondents from the area of Bhaktapur, Nepal. This set of data was used by the author to understand the safety situation of the construction workers' in Nepal after the disaster (refer to chapter 5). Another target to the case study was also to do a feasibility study if a big scale in depth semi structured interview is possible to investigate further with the context of Nepal Earthquake 2015.

After conducting the small scale interviews with 14 respondents, interviewers formulated another detailed questionnaire. In this step, they conducted 24 more interviews with different stakeholders of PDR. Author of this thesis collected the second set of secondary data for an in depth understanding of the safety situations and the factors affecting health and safety of the construction workers during PDR phase (refer to chapter 6). The respondents were selected and interviewed strategically by the interviewers to represent a wide range of perspectives. As the following table 6 shows the number and type of participants that participated in the interview; one owner, two government officials, four general contractors, thirteen engineers, eight supervisors and ten construction workers have been interviewed.

Table 6: List of Participants from Nepal

\begin{tabular}{cc}
\hline Participants' Type & No of Participants \\
\hline Owner & 1 \\
\hline Government Officials & 2 \\
\hline General Contractor & 4 \\
\hline Engineer & 13 \\
\hline Supervisor & 8 \\
\hline Worker & 10 \\
\hline Total & $\mathbf{3 8}$ \\
\hline
\end{tabular}


The participants were well informed of the aim of the interviews, and they were willing to participate. All the interviews were conducted in the area of Bhaktapur, Nepal. The respondents were asked to describe their perspective in as detail as possible. Semi structured questions allow the respondents to choose the direction in which they want to answer the questions. Follow up questions were also posed to encourage the respondents to reflect further upon their responses and to clarify their concerns.

The interviews were conducted in Nepali though the questionnaires were formulated in English. The author is highly indebted to the professor and students of the Department of Civil Engineering at Khwopa Engineering College, Nepal for conducting the interviews with local people and giving open access to their data set for this study. The interviews were translated and transcribed in English simultaneously by the interviewers. The responses were recorded using an audio recorder. All the respondents' identities were kept anonymous during the process by assigning the respondents with a user ID. The transcribed responses were initially analyzed independently, pointing out and identifying information that is directly relevant to the context of this study. The questions and responses were divided into five different categories for the pilot study and seven other categories for the second round of analysis to get the most out of this study.

\subsection{Qualitative Data Analysis}

Data analysis is the part of qualitative research that most clearly differentiates it from quantitative research methods [62]. The goal of the qualitative analysis is the transformation of qualitative data into findings. It is worthwhile to note that there is no specific formula to guide that transformation of data to findings [63]. It is indeed a 
challenge to make sense of huge amounts of data by "reducing the volume of raw information, sifting trivia from significance, identifying significant patterns, and constructing a framework for communicating the essence of what the data reveal" [64]. One way to arrive at the findings is to identify patterns in the data. However, finding uncertainties and ambiguities is another.

The amount of data generated by qualitative methods is extremely large, particularly when compared with traditional quantitative data collections, and making sense of pages and pages of interviews and field notes can be overwhelming. Organizing and analyzing the data can appear to be an impossible task [63]. One way to accomplish this daunting task is by hand, a method still employed by some qualitative researchers. However, more than a few noted qualitative theorists have encouraged the use of qualitative data analysis software tools designed to manage data more efficiently throughout the course of a research project. Software that assists in the analysis of qualitative data is referred to as ComputerAssisted Qualitative Data Analysis Software (CAQDAS). There are three basic types of software used in the analysis of qualitative data. Some only retrieve text; others code and retrieve text; still others are referred to as theory-building software.

One of the popular packages used for qualitative research purposes is NVivo by Qualitative Solutions and Research Pty. Ltd. of Melbourne, Australia. A recent text [65] has offered the beginning researcher an overview of data creating decisions and explanations for which analytic tools fit best. The book comes with a software demo so that the reader can sample some of the tools available in QSR's NVivo. NVivo "combines the coding of rich data with familiar ways of editing and revising rich text" and is easier to 
introduce to students than other packages. Also, the software can be learned during the actual research process rather than in lengthy preparatory training phases.

NVivo provides a variety of tools for manipulating data records, browsing them, coding them, and annotating and gaining access to data records quickly and accurately [66]. NVivo has tools for "recording and linking ideas in many ways, and for searching and exploring the patterns of data and ideas. It is designed to remove rigid divisions between 'data' and 'interpretation,' should that be the researcher's goal. It 'offers many ways of connecting the parts of a project, integrating reflection and recorded data" [66]. As the researcher links, codes, shapes, and models data, NVivo assists in the management and synthesis of ideas. It offers a range of tools for pursuing new understandings and theories about the data and for the construction and testing of answers to research questions. The tools used for this study are described below.

\subsubsection{Theme Identification using Nodes}

All the target articles are first feed into the file section of Nvivo. As specified in the systematic literature review methodology section; all the articles were screened using the parameters set in the methodology. The parameters were examining title, abstract, keywords, finding and references. Figure 3 shows the process of feeding the articles in the database of Nvivo and then identifying the themes according to the context of the article. 


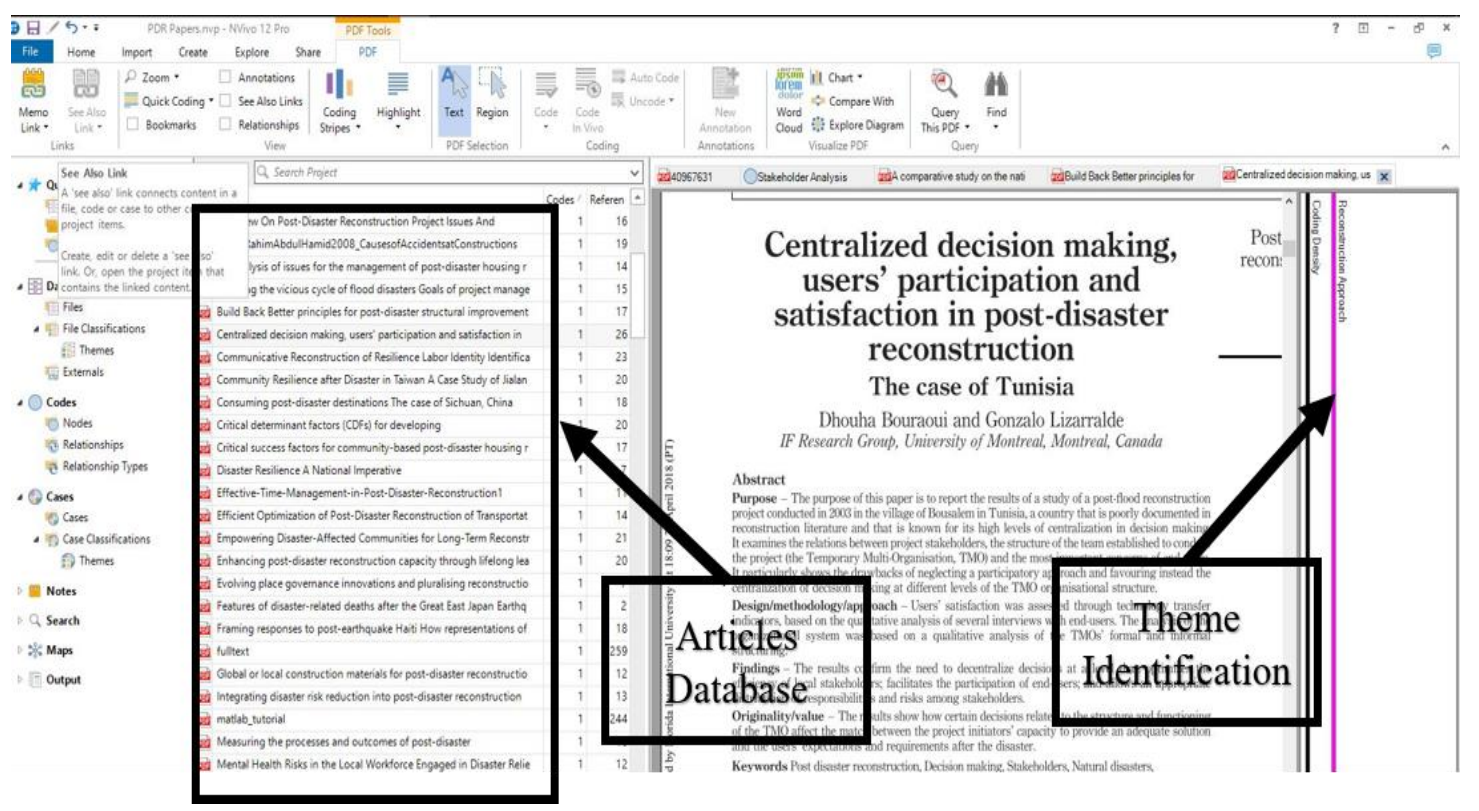

Figure 3: Theme Identification in Nvivo

After going through the parameters of the articles, the theme of the article was identified. Every scholarly article has some specific objectives and scope within the context of the study. The author studied each of the articles to find out which theme the target article belongs to. After identifying the themes, articles were coded using the theme name and put into different nodes. Figure 4 clarifies the use of nodes in the theme identification process in Nvivo. 


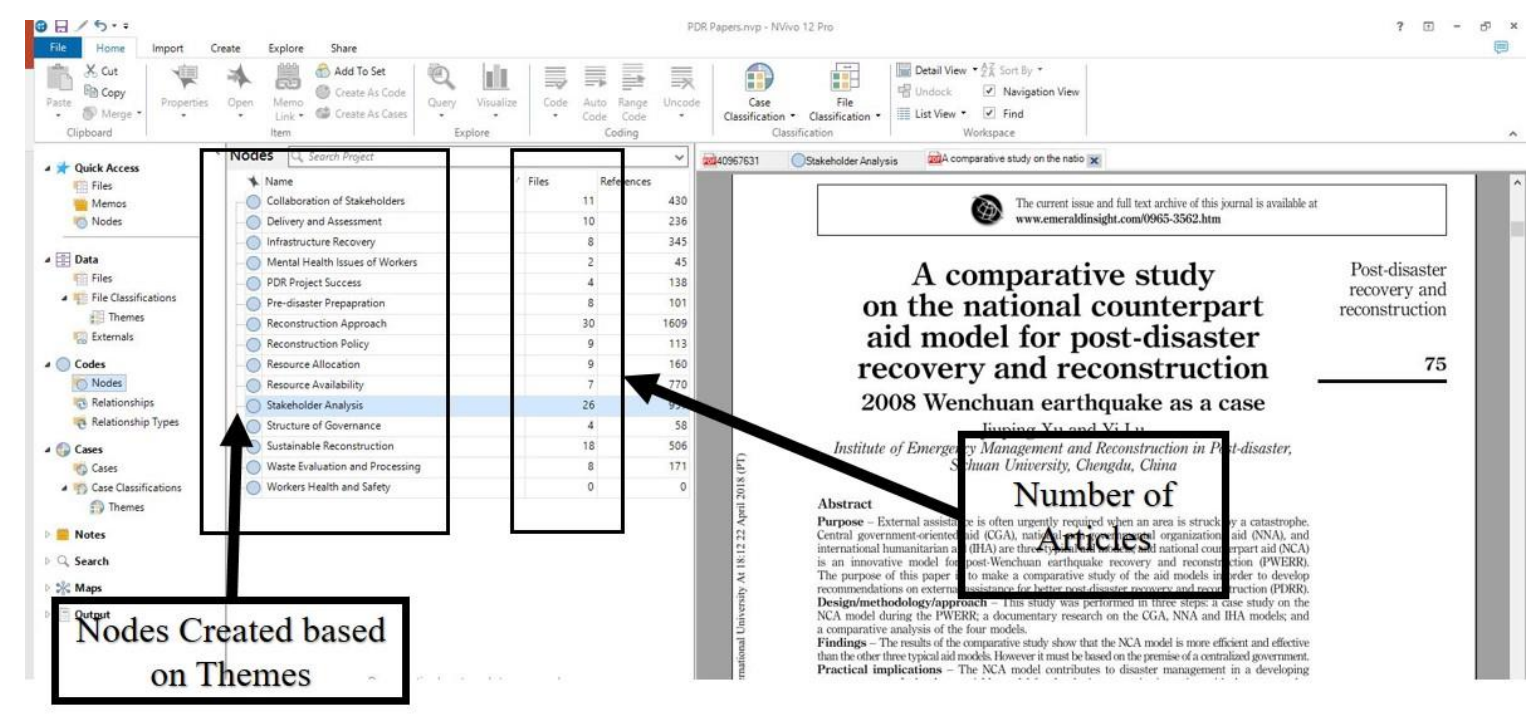

Figure 4: Nodes and Frequency of Publications in Nvivo

\subsubsection{Quotation Method}

Another important tool that Nvivo has is to code the texts according to their themes thus creating nodes of those identified themes. In this study, transcriptions were first read thoroughly, and then the texts were coded according to their respective themes and nodes. The safety factors that we come up with from this qualitative analysis are backed up with the respondents' quotes. For example; if author claim that the Worker-01 indicated that the use of personal protective equipment (PPE) is important at the construction job site, it is then backed up by the respondent's response as follow:

"Yes. It is indeed important for us to use safety boots, helmets, and gloves. Otherwise, we might get hurt while working on the site." 


\subsubsection{Matrix Coding Query}

In Nvivo, Matrix coding query is another tool that lets us see the intersection and relationship between two lists of items. It forms a table containing a list of item in the rows and another list of item in the column thus showing a relationship between the items. In this study, matrix coding has been done between the different demographics of the respondents and created safety factors as in nodes.

\subsubsection{Word Query}

Word query is a tool in Nvivo that helps to identify the most frequently used words among the target papers. In this study, a word query analysis would certainly help to understand what are the most frequently used words during the interviews and what are the issues respondents are mostly concerned about. 


\section{CHAPTER 4}

\section{Knowledge Gap Analysis}

This chapter contributes towards the fulfillment of the first objective of the study which identifying a knowledge gap in the literature of post disaster reconstruction in terms of construction workers' health and safety. The analysis and findings of this chapter identify a significant knowledge gap in the existing literature thus opening a door for further investigating through case study and in depth interview analysis. Introduction

\subsection{Introduction}

It is reported that at least 250 natural disasters occur every year around the world and the number of natural disasters is increasing every year [1]. In the coming years, the frequency and magnitude of disasters are expected to be increased due to climate change, and the impact on physical properties is going to be extreme nevertheless [19]. PostDisaster Reconstruction (PDR) is one of the phases of recovery after a disaster. However, concrete definition, scope, and activities are yet to be defined for Post-Disaster Reconstruction (PDR) phase. Many scholars agree that PDR is a complex issue to be addressed and one of the most challenging phases to pass since they come along with uncertainties and complexities. Despite having more uncertainties and complexities than regular construction, no significant study has been conducted to find out the differences between regular construction and PDR. Due to a lack of study, it is assumed that PDR projects are not different from regular construction projects, while [8] pointed out the differences between these two in terms of legislation. However, no study so far has defined how the PDR phase is different from regular construction in terms of construction workers' health and safety. 
A 2008 study stated that most of the disaster-related injuries happen to construction workers during the PDR process and they are prone to all the construction hazards similar to regular construction hazards but with greater exposure [39]. Centers for Disease Control and Prevention reports that increasing injury trends, identified illness cluster, and unconfirmed illnesses have been observed among the workers involved in PDR [43] which proves that construction workers at PDR sites are not only vulnerable to construction hazards, but they are also exposed to illnesses; both identified and unidentified. In addition, many other articles noted how dangerous and risky PDR projects could prove to be for construction workers in terms of health and safety. This paper intends to identify a gap in the literature in the area of PDR through literature review thus revealing how PDR is different from regular construction projects in terms of construction workers health and safety.

\subsection{Objective and Scope}

The main objective of this chapter is to reveal the knowledge gap in the area of construction workers' health and safety in the PDR phase through a literature review. Authors have focused on the reconstruction projects; both housing and infrastructure, taking place only after natural disasters and within the affected geographical area. This paper presents the preliminary outcome of the literature review.

\subsection{Methodology}

This paper is based on the findings from the review of existing literature on PDR. The paper explores how the literature on PDR has a knowledge gap in terms of construction workers' health and safety. To pursue this objective, the systematic literature review (SLR) 
methodology has been adopted. A systematic literature review gives a good understanding of the background of the study and researches that have been carried out so far within the boundary of the objective of the study. Many scholars such as Yi \& Yang, 2014 and Shafique \& Warren, 2016 and many more have been identified using the methodology to carry out extensive literature reviews and spotting knowledge gaps in the past as well.

To conduct this systematic literature review study, a three level of literature review has been done. Figure 5 shows the flowchart of the methodology adopted for this literature study. In the first level of the search procedure, some specific keywords are chosen within the area of PDR. The keywords are "post-disaster reconstruction", "reconstruction after disaster", "post-disaster recovery", "recovery after reconstruction", "post-disaster rebuilding", "construction workers" safety", "safety at post-disaster reconstruction", “workers' safety issues of post-disaster reconstruction", "and occupational risks at postdisaster reconstruction”. Google scholar has been used as the literature-searching platform for this study. Each keyword has been used once in the search bar to initiate the literature search, and for each keyword, the first 50 search results were targeted for visual examination. To increase the possibility of covering all the materials regarding the topic of this study, technical reports, governmental and non-governmental reports, thesis works and newspaper articles are also taken into consideration as existing literature. 


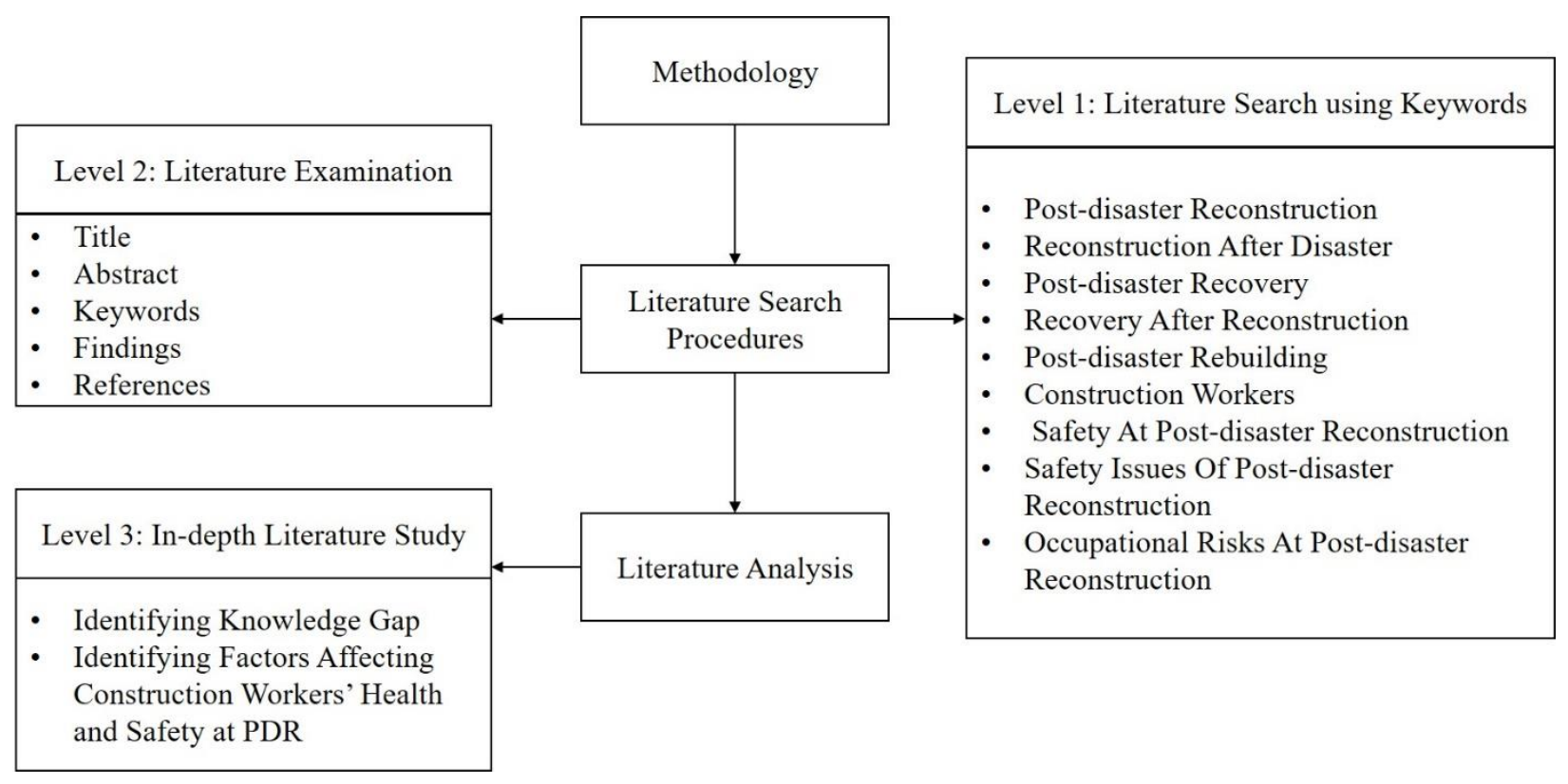

Figure 5: Flowchart of the Methodology

In the second level of the literature review, the targeted literature are narrowed down by examining the Title, Abstract, Keywords, Findings, and References of the research papers to identify if any paper is directly related to "Construction Workers' Health and Safety at PDR Phase." The third level of review is done followed by the previous one where all the target papers were studied thoroughly to achieve the objective of this study by finding out the knowledge gap in PDR literature and identifying the factors affecting workers' health and safety.

\subsection{Understanding Post-disaster Reconstruction (PDR) Phase}

According to [67], complete recovery after a disaster is to reach a state equal to or better than the pre-disaster state. Complete recovery from the impact of disasters has several phases and stages comprising of multiple activities to be done within the phases. Response and Recovery are the two main stages that take place after a disaster consisting of several 
other phases and activities [8]. According to [68], disaster recovery has four phases, e.g. Disaster Assessment, Short Term Recovery, Long-term Reconstruction and Recovery Management.

Considering the definitions and information extracted from the literature, authors believe that PDR is a phase that comprises of activities involving and including debris management, construction, and repairing of structures and demolition, restoration, and retrofitting of damaged structures that are performed after the disaster until the complete recovery is achieved within the affected geographical area. Figure 6 shows the breakdown of the recovery process after a disaster.

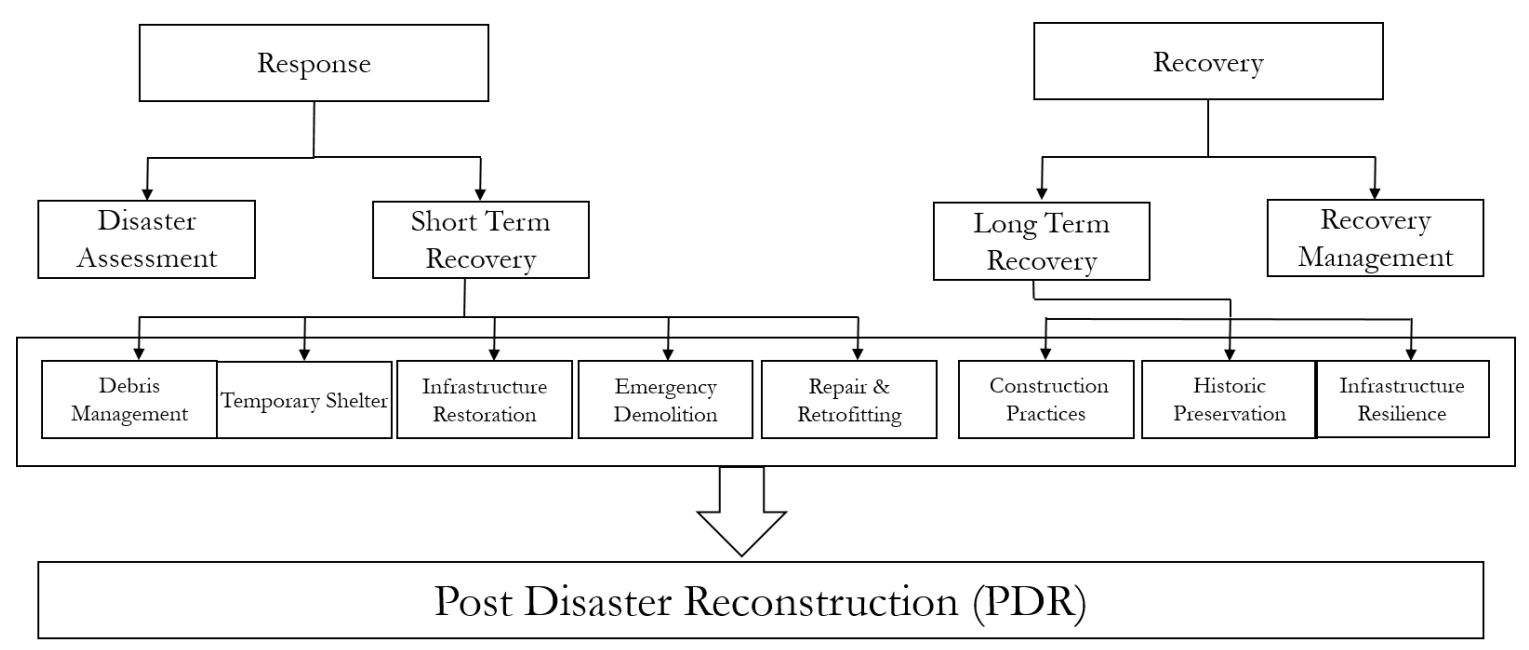

Figure 6: Activities of Post Disaster Reconstruction (PDR) Phase

Following the diagram, Disaster Assessment, and Short Term Recovery phase fall under the Response stage while Long Term Recovery and Recovery Management phase fall under the Recovery stage. There are several activities within these four PDR phases, but in this study, authors have identified eight activities from short-term recovery and long- 
term recovery phases that also belong to PDR thus defining the definition of PDR phase. It is worthwhile to note that the PDR phase may exist separately or simultaneously with other phases after a disaster; however, no concrete demarcation exists among them in terms of sequential implementation.

\subsection{Discussion and Findings}

As specified in the methodology, a systematic literature review has been done to find out a knowledge gap in the literature of Post Disaster Reconstruction (PDR). After studying and analyzing 155 target articles published from the year 2000 to 2018, the following themes were identified to the topic of research within the context of PDR. The analysis showed that the mostly studied theme in the last 18 years is reconstruction approach and stakeholder analysis. However, construction workers being one of the most important stakeholders of PDR, their health and safety was never a concern of research among scholars. A similar kind of study was done by Yi and Yang (2014); however, they studied the articles published until 2012. They also didn't find any significant study on construction workers health and safety during PDR. Table 8 below shows the adapted and modified findings from that study. These findings have been refined from the year 2000 to 2018 adapting the same methodology. The table shows that no scholarly article has been

published from 2000-2018 on construction workers' health and safety with the context of post disaster reconstruction. 
Table 7: Number of Publication from 2000-2018 [Adapted and Modified from (Yi \& Yang, 2014)]

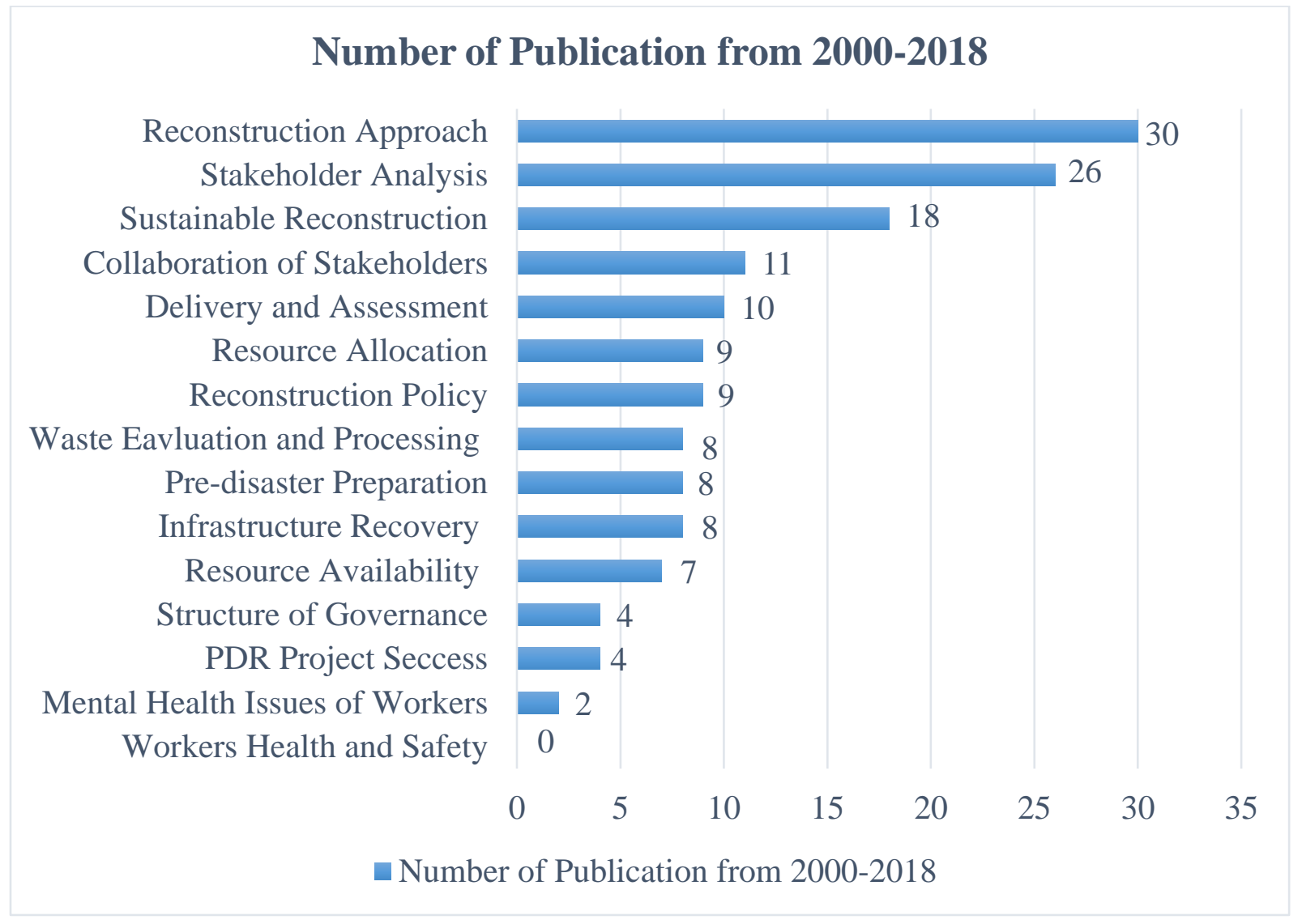

Construction Industry is one of the most dangerous industries in terms of health and safety due to its own dynamic nature. Construction activities pose a great challenge to the health and safety of the workers. Among the other industries, construction ranks one of the tops in terms of fatality. Many literatures have already stated and agreed that the construction industry has one of the highest fatality rates in the world. From 2003 to 2016 more than 13,500 workers have died on the construction industry averaging more than 960 deaths per year and 5190 fatal work injuries occurred in the US [25]. There are various causes of construction accidents that affect the health and safety of construction workers and scholars have been addressing them in an extensive way over the past decades. 
Nevertheless, when it comes to PDR projects, workers' health and safety have not been a popular topic of research among the scholars while reconstruction during post-disaster period makes it more vulnerable and prone to construction hazards [69]. Following the review study conducted by [11], it has been observed that construction workers health and safety is not a theme of research that scholars of PDR have been addressing distinctly where PDR projects can have significant effects on construction workers health and safety. Many scholars noted several factors of PDR, different from regular construction projects, that has a direct effect on construction workers health and safety but have not been distinctly studied. Following sections describe the factors pertaining to the health and safety of construction workers in the PDR phase.

\subsubsection{Health and Safety with Debris Management}

PDR process starts with the removal and management of debris that occurs due to natural disasters. Proper and early removal of debris is important after the disaster, but at the same time, it is a risky job. Different types of disasters bring different types of debris along with it. In one of their reports, FEMA categorized disasters in seven types based on their debris producing nature and these seven types of debris producing disasters are Hurricanes, Tsunami, Tornadoes, Floods, Earthquakes, Wildfires and Ice Storms. They also highlighted nine types of debris that are produced during these different types disaster namely Vegetative, Construction \& Demolition, Hazardous Waste, White Goods, Soil, Mud \& Sand, Vehicles and Vessels, Putrescent Debris, Infectious Waste, and Chemical Debris and each of them carries their own risks and potentiality of hazards to human health. The presence of hazardous and contagious debris makes the PDR sites more vulnerable in terms of health and safety [69]. Centers for Disease Control and Prevention reports that 
increasing injury trends due to identified illness cluster and unconfirmed illnesses have been observed among the workers involved in PDR [43] which proves that Construction Workers at PDR sites are exposed to illnesses, both identified and unidentified.

\subsubsection{Participation of Community People}

It has been observed in many cases that after natural disasters, there is a huge lack of construction workers to initiate the reconstruction process. This deficiency is usually met in three ways in a disaster-affected area, e.g. participation of community people in PDR, use of unskilled workers and importing workers from nearby countries. Though participation of community people in PDR has always been encouraged by the governments, NGOs and scholars, it has its own risks and challenges. [55] expressed their concern regarding the little knowledge and applicability of this solution to the shortage of workers during the PDR phase. Community people without the required knowledge or skill of construction are always vulnerable and exposed to hazards. It is also worthwhile to mention that most of these community people who participate in reconstruction works are also disaster survivors as well. Working at the PDR sites, confronting their own devastated homes and the dead bodies of their own people, often lead them to Post-Traumatic Stress Disorder (PTSD) and Depression. It has also been observed that PTSD often leads the sufferer to suicidal attempts [44]. Moreover, construction work has been identified to be one of the most stressful work both physically and mentally. The stress and trauma increase the possibility and probability of accidents for construction workers at workplaces, and when it comes to PDR works, it becomes more significant. 


\subsubsection{Use of Unskilled Workers}

While we are talking about the risks associated with the participation of community people in reconstruction projects, the hired/appointed construction workers are also prone to hazards/fatalities no less than the community people due to lack of skill, experience or knowledge of working at PDR projects. Construction workers can be divided into three categories based on their required skill set, e.g. Unskilled Workers, Semi-skilled Workers, and Skilled Workers. Generally, skilled workers are involved in specific works that require skill or decision making the ability to some extent whereas semi or unskilled workers are involved in works that do not require skill or decision-making ability. Following a study in Malaysia, where 100 construction accidents were analyzed, it is seen that even semi-skilled and skilled workers were involved in $60 \%$ of the accidents due to the nature and complexity of the construction work [70]. During the PDR phase, a shortage of skilled workers and the use of unskilled have been identified in the media and in scholarly articles as well. Moreover, after a major natural disaster and heavy loss of structures, the main focus moves to the faster restoration of structure and temporary shelters and shifting the affected people to their shelters. To accelerate the restoration process, a high inflow of financial aid for the reconstruction projects get in from ally nations, NGOs, INGOs. In response to the disasters and loss of homes, many international organizations, e.g. Red Cross and World Bank come forward with financial aids helping the nations to overcome from the impact of the disasters. Majority of the World Bank's PDR loans are used for housing reconstruction in affected areas. As a result, the government and construction companies urge to build as many structures as early as possible [49] resulting in 'Building Back Faster' syndrome. Because of that, they compromise with the construction workers' skills and expertise thus 
overall health and safety. With less skilled work force, they became more exposed to construction hazards. This scenario of using less or unskilled workforce due to lack of skilled workers has been observed after the tsunami in Aceh and Sri-Lanka 2004, [14] Nepal Earthquake 2015 [50] and Haiti Earthquake 2010 [52]. It is true that after a disaster, emergency action and attention are required at the affected area and there is usually no time to hire and appoint skilled work force but addressing this issue and preparing the construction workers and even the community people to some extent will definitely help to solve the issue.

\subsubsection{Importing Workers}

Importing workers from other countries is an ancient theory, which has been practiced for centuries in this world. One of the main reasons for importing construction workers is cost reduction since workers' cost accounts for $30-60 \%$ of the total cost of construction [71]. However, during the PDR phase, a shortage of construction workers is the main reason for importing construction workers from nearby countries [38]. However, it is often observed that imported workers have been subjected to exploitation in terms of wages, facilities and also safety equipment [15]. After the hurricane Katrina, it has been observed that most of the construction workers for reconstruction works were immigrants, both documented and undocumented. It has been reported that those workers were exploited by their employers thus exposing them to more construction hazards by not providing enough safety training and safety equipment. According to OSHA, Personal Protective Equipment (PPE) is one of the most effective ways to deal with many construction hazards, and the use of PPE is required by OSHA standard as well. About 2 million workers at risk of workrelated injuries each year of which $25 \%$ are head, eyes, eyes, hands, and feet related which 
can be protected using PPE [26]. Construction workers are at great risk if they do not use PPE or they use damaged PPE. The absence of PPE or not using PPE has been identified as one of the major factors for Construction accidents in the literature over the years [28]. Not only PPE, but equipment without safety devices are also a major reason for construction accidents [72]. On top of that, because of being foreigners they had difficulty understanding the language of instruction, safety signs on devices and communicating at PDR projects [38]. It has also been noted that imported/migrant workers suffer from a febrile illness where febrile illness refers to the known sickness (such as fever) but with unknown or unidentified cause. And they are more prone to occupational hazards and health issues than local workers [73].

This literature study shows there are several factors, both common and unique, that contribute to the health and safety of PDR workers. Among the common, the factors 'use of unskilled workers', 'lack of Personal Protective Equipment (PPE), and 'lack of training' are the major ones but they have their own background and significance in terms of PDR. Authors believe the traditional way or technique may not be well enough to address the aforementioned issues of PDR projects. Through the literature review, a few factors are also identified that are unique to regular construction and contribute to the health and safety of the construction workers at PDR projects. Among them, 'exposure to hazardous and contaminating debris,' 'building back faster syndrome,' 'imported workers,' 'posttraumatic stress disorder' are a few of the major contributing factors that are not usually seen in the regular construction projects. 


\subsection{Conclusion and Future Works}

Natural Hazards affect human life in many ways, and one of the major aspects of them is health and safety. Workers involved with PDR projects are more exposed to fatal hazards in a substantial way compared to workers involved in regular construction. Unfortunately, no distinct study has been done so far on this topic neither any specific data is available for PDR projects regarding fatality of construction workers. Although many aspects of PDR have been moderately studied and analyzed over the past years [11], the construction workers' safety has been untended to be considered as a distinct theme of research. No major articles or studies have evaluated the health and safety of construction workers' at PDR projects whereas the safety of construction workers' at regular construction projects has been extensively studied. On top of that, no significant research has been done so far on the differences or similarities between regular construction projects and PDR projects. However, this literature paper shows that many researchers have noted the significance of PDR in terms of health and safety of construction workers. Studying PDR on the context of construction workers' health and safety can lead to some effective measures that will contribute to reducing the fatality rate in PDR projects and in the construction industry overall. This literature review paper signifies the need for attention and research in this area of interest.

The author intends to continue studying the differences between regular construction and PDR in terms of health and safety to establish the lines of demarcation. A further study is also required to identify factors affecting the health and safety of construction workers at PDR projects through factor analysis. After identifying specific factors affecting the health and safety of construction workers, qualitative analysis of the factors will be done 
to find out the significance of each contributing factors. Authors also intend to conduct interviews with different stakeholders of PDR projects to acquire different perspectives on the issue. After recording the semi-structured interviews, data will be coded, condensed and analyzed to understand the concept of constructing knowledge about the interrelated issues and deep structure of the data. This analysis will also facilitate the construction of relational networks by identifying the content and structure of respondents' opinions. 


\section{CHAPTER 5}

\section{Worker Health and Safety during Post-Disaster Reconstruction: A pilot study}

This chapter is based on a small scale case study conducted in Bhaktapur, Nepal with the context of this study. This case study helped to remodel and formulating the questionnaire for the thesis. The finding of this case-study also significantly influenced the further in-depth interviews and investigation of construction workers' health and safety during post disaster reconstruction phase.

\subsection{Introduction}

The construction industry is one of the most hazardous industries in the world. Both the number of people employed and death rates are higher in the construction industry compared to others. The construction industry of Nepal is no different from the rest of the world, where construction constitutes the fifth highest population in terms of occupation in Nepal [74]. Joshi et al. (2011) identified construction to be one of the most hazardous industries in terms of health and safety for the workers in Nepal [75]. However, there is no specific statistics available on the rate or number of accidents of construction workers in Nepal.

Nepal is passing through a post-disaster recovery phase now after the disastrous impact of the 2015 earthquake. However, the reconstruction process is very slow, and the country is facing many problems including lack of workers, unavailable resources and others [76]. Only $14 \%$ of the structures have been rebuilt in the last three and a half years [77] which indicates that the reconstruction phase will last for several more years in Nepal. During these three and a half years of reconstruction works, no statistics or data has been generated 
nor has any study been done to investigate the health and safety of the construction workers. Many studies show that post-disaster reconstruction (PDR) is risker and more prone to construction hazards than regular construction [39]. Since the reconstruction is expected to last several more years engaging construction workers, their health and safety is a major area to focus on.

This chapter investigates on the construction workers' health and safety situation after Nepal earthquake 2015. This study is based on the case study of Bhaktapur, Nepal. The adopted methodology is a qualitative analysis of semi-structured interviews and is exploratory since no study has been done on the workers' health and safety during postdisaster reconstruction in Nepal before.

\subsection{Bhaktapur, Nepal, and Earthquake of 2015}

Nepal is one of the most earthquake prone country in the world. On April 25, 2015, a major earthquake hit Nepal with a magnitude of 7.8 Richter scale at Gorkha. The earthquake was followed by numerous aftershocks. Around 9,000 people lost their lives, hundreds of thousands lost their houses, and the estimated economic damages were around \$10 Billion [78].

Bhaktapur is one of the most severely affected cities by the earthquake in Nepal. Bhaktapur is an ancient and historic city, located along the eastern margin of the Kathmandu valley. Many iconic heritage sites of this city, for instance, Durbar Square and Vatsala Durga Temple were severely damaged. Structural damage was extensive to the mostly unreinforced brick structures. The Nepal earthquake caused heavy brick facades to collapse into the narrow alleys within the historic areas of Bhaktapur [79]. The magnitude 
7.3 aftershock on May 12, 2015, was located approximately $40 \mathrm{~km}$ east of Bhaktapur and caused significant additional damage to already weakened structures [80]. Along with the historic temples and monuments, people also lost their houses and shelter due to this major earthquake. The Himalayan Times, (2017) reported that even after 2 years of the earthquake, debris and rubbles were seen in many places. Structures were still damaged, some being held up by temporary supports (Nepali: teka) while some others were being demolished. They also reported the reconstruction works of the damaged structures was going at full speed.

Bhaktapur is one of the major cities where reconstruction works are going on in full swing; authors perceived that Bhaktapur could be a good case study for the analysis of construction workers' health and safety during post-disaster reconstruction.

\subsection{Objective and Scope}

The objective of this chapter is to understand the health and safety condition of construction workers during post-disaster reconstruction in Bhaktapur, Nepal. This chapter studies how the health and safety of construction workers are affected by the disaster in the context of the 2015 Nepal earthquake. This qualitative study is based on in-depth semistructured interviews. It investigates the different aspects of workers' health and safety in PDR; for instance, use of Personal Protective Equipment (PPE), safety training, the involvement of immigrant workers, differences between regular construction and PDR, and situation before and after Nepal earthquake 2015 from the perspectives of different stakeholders. 


\subsection{Methodology}

This chapter is done following a qualitative and exploratory method. An exploratory study is appropriate when little or no previous information exists about the study subject. This study aims to capture and describe the perspective of different stakeholders of the PDR phase in Bhaktapur, Nepal. The qualitative data has been collected from the secondary source. As explained in Chapter 3, section 3.3.2, the first set of secondary data has been used for this chapter to conduct a pilot study. The respondents were selected and interviewed by the interviewers strategically to represent a wide range of perspectives.

As shown in Table 8, one owner, two general contractors, four engineers, three supervisors, and four construction workers, in total fourteen stakeholders were interviewed following a semi-structured questionnaire. This set of data has been analyzed to understand their perspective on construction workers' health and safety during PDR.

Table 8: Participants Type and Number

\begin{tabular}{|cc|}
\hline Participants' Type & No of Participants \\
\hline Owner & 1 \\
\hline General Contractor & 2 \\
\hline Engineer & 4 \\
\hline Supervisor & 3 \\
\hline Worker & 4 \\
\hline Total & $\mathbf{1 4}$ \\
\hline
\end{tabular}

The participants were well informed of the aim of the interviews, and they were willing to participate. All the interviews were conducted in the area of Bhaktapur, Nepal. The respondents were asked to describe their perspective in as detail as possible. Semi structured questions allow the respondents to choose the direction in which they want to answer the questions. Follow up questions were also posed to encourage the respondents to reflect further upon their responses and to clarify their concerns. 
The interviews were conducted in Nepali though the questionnaires were formulated in English. The responses were recorded using an audio recorder. The interviews were translated and transcribed in English simultaneously by the person conducting the interviews. All the respondents' identities were kept anonymous during the process by assigning the respondents with a user ID. The transcribed responses were initially analyzed to point out and identify information that is directly relevant to the context of this study.

The semi-structured questionnaires were designed to extract information from the respondents in several categories. The questions were divided into five categories each having sub-categories and follow up questions. Table 9 shows the categories of the questionnaire, their sub categories and the description of the content.

Table 9: Category and Sub-category of Questionnaire

\begin{tabular}{|c|c|c|c|}
\hline SN & $\begin{array}{c}\text { Category of } \\
\text { Questions }\end{array}$ & Sub-category & Description of Content \\
\hline $\begin{array}{c}\text { Category } \\
1\end{array}$ & $\begin{array}{l}\text { Difference } \\
\text { between } \\
\text { Regular } \\
\text { Construction } \\
\text { and Post- } \\
\text { Disaster } \\
\text { Reconstruction } \\
\text { (PDR) }\end{array}$ & $\begin{array}{c}\text { Major } \\
\text { Differences }\end{array}$ & $\begin{array}{l}\text { The questions associated with this category were } \\
\text { asked to identify the different perspective of } \\
\text { different stakeholder on the differences between } \\
\text { these two types of construction. }\end{array}$ \\
\hline $\begin{array}{c}\text { Category } \\
2\end{array}$ & PPE in PDR & $\begin{array}{l}\text { Importance } \\
\text { Availability }\end{array}$ & $\begin{array}{l}\text { PPE is one of the most effective ways to deal with } \\
\text { possible hazards on the construction site. The } \\
\text { associated questions with this category revealed } \\
\text { what the respondents think about the use of PPE on } \\
\text { both regular and reconstruction sites. }\end{array}$ \\
\hline $\begin{array}{c}\text { Category } \\
\mathbf{3}\end{array}$ & $\begin{array}{l}\text { Involvement } \\
\text { of Immigrant } \\
\text { worker }\end{array}$ & $\begin{array}{l}\text { Language } \\
\text { issues } \\
\text { Understanding } \\
\text { of Instruction } \\
\text { Labor Rights } \\
\end{array}$ & $\begin{array}{l}\text { Nepal being a multilingual country, the questions } \\
\text { from this category revealed the involvement of } \\
\text { stakeholders from different regions of the country } \\
\text { and their associated issues. }\end{array}$ \\
\hline $\begin{array}{c}\text { Category } \\
4\end{array}$ & $\begin{array}{l}\text { Safety } \\
\text { Training }\end{array}$ & $\begin{array}{l}\text { Importance } \\
\text { Occurrence } \\
\text { Frequency }\end{array}$ & $\begin{array}{l}\text { Safety training has been proved to be one of the } \\
\text { most effective ways to prepare people for } \\
\text { preventing possible hazards. Questions were asked } \\
\text { about the safety training and its importance } \\
\text { according to different respondents. }\end{array}$ \\
\hline
\end{tabular}




\begin{tabular}{cccc}
\hline SN & $\begin{array}{c}\text { Category of } \\
\text { Questions }\end{array}$ & Sub-category & Description of Content \\
\hline $\begin{array}{c}\text { Category } \\
\mathbf{5}\end{array}$ & $\begin{array}{c}\text { Safety } \\
\text { Concerns } \\
\text { before and } \\
\text { after the } \\
\text { Earthquake }\end{array}$ & $\begin{array}{c}\text { Safety } \\
\text { situation } \\
\text { before disaster } \\
\text { Safety } \\
\text { situation after } \\
\text { the disaster }\end{array}$ & $\begin{array}{c}\text { Questions associated with this category are meant } \\
\text { to reveal the before and after situation of safety } \\
\text { culture and measures on construction sites in } \\
\text { Nepal. }\end{array}$ \\
\hline
\end{tabular}

\subsection{Issues Pertaining to the Health and Safety of the Construction Workers}

\subsubsection{Differences between Regular Construction and PDR}

Respondents were first presented with the definition of PDR to clarify their concept. PDR was defined to the respondents as "Construction works taking place after a disaster within the disaster-affected area. The works might include debris management, repairing, retrofitting and restoration of the structure, demolition of structures and construction of structures until full recovery is achieved". After clarifying the concept of PDR and regular construction, respondents were asked about their opinions if they think PDR is different from regular construction in terms of workers' safety and health.

All the respondents agreed that PDR works are different from regular construction works and pointing out the risks associated with PDR works. One of the engineers, Engineer-501 responded, "Yes, post-disaster reconstruction is very different from the routine construction site. PDR sites are riskier to work as compared to regular construction site," and Supervisor-503 responded similarly saying "Yes, It is riskier. We have to think about many things in PDR that we do not consider in regular construction" thus stating the potential risks of PDR. One of the workers, Worker-501 expressed his concern regarding the available working space and stability of the affected structure in repairing and restoration works after a disaster. He responded, "It is riskier. It is because 
we do not get the proper spaces to work on the structures. There is debris here and there. The structures are not stable. We are always at risk". Another worker Worker-502, despite having no experience of working in the PDR sites, said, "There must be significant differences. I think PDR sites are riskier to work, but I don't have any experience working on PDR sites". Another engineer in charge, Engineer-504, expressed his concern in more detail figuring out issues such as time constraints, workers shortage, and poor management in PDR sites. Upon asking what he thinks about the possible differences between regular and PDR, he said, "It sure is different. We faced more risks while working on PDR than regular construction. We had an issue with time, worker shortage and poor management. It's really difficult and risky to work on PDR". While Supervisor-502 pointed out issues with emergency demolition since he was assigned to the demolition works in Bhaktapur. He said, "Yes, they are different. Generally, in the PDR sites, old houses are built really close, and it becomes difficult to demolish one house without affecting the house attached to or nearby it. And sometimes arguments may arise among the owners".

\subsubsection{Use of Personal Protective Equipment (PPE)}

According to OSHA (2016), Personal Protective Equipment (PPE) is one of the most effective ways to deal with many construction hazards [26]. About 2 million workers at risk of work related injuries each year, of which $25 \%$ are head, eyes, eyes, hands, and feet related, can be protected using PPE. Construction workers are at great risk if they don't use PPE or they use damaged PPE. The absence of PPE or not using PPE has been identified as one of the major factors for Construction accidents in the literature over the years [28]. Not only PPE, but equipment without safety devices are also a major reasons for construction accidents [72]. 
The author wanted to explore the scenario in Bhaktapur, Nepal regarding the use of PPE in construction works. It seemed that all the respondents are aware of PPE though not by the term PPE, but they know about the safety equipment that can be used while working. Upon asking about what do they know regarding the PPE, they randomly named certain PPEs such as hard hats, safety boot, gloves, and glasses. Their responses revealed that despite being aware of the safety issues and use of PPE, nobody cared to use PPE or provide PPE in the construction sites. Worker-502 replied on the question whether they are provided with PPE on reconstruction sites, "No, only big companies provide safety equipment. We don't get such equipment in reconstruction sites". On the other hand, two other workers stated they do not get PPE even in the bigger construction sites or while working with bigger companies. When we asked the question to the owner and contractors about providing PPE to the workers, they replied in the negative. The Owner-501 responded, "We don't provide any PPE. Boots and gloves are provided only if required." and he added upon a follow up question on the importance of PPE, "It is necessary for everyone involved in construction sites, but we haven't provided any PPE yet. We never compel the workers to work putting themselves on physical risk. There might be a chance of an accident, but one should always be careful'. Contractor-501 also agreed that they usually do not provide safety equipment to the worker saying, "No, we don't provide other workers with the safety equipment or any other equipment" while Contractor-502 understood the importance of PPE and said, "Safety is the must. It is necessary for all workers \& me. But, no attention has been paid to safety. Just like there is no provision of PPE (helmets, boots)". When the same question was asked to the engineer in charge, Engineer-504 expressed his concern regarding safety issues and stated, "Obviously PPE is 
important. PPE can save from many unwanted injuries and hazards. But unfortunately, we were not provided with any. I wish we could make the use of PPE mandatory on construction sites".

\subsubsection{Involvement of Immigrant Workers}

Importing workers from other countries or regions is not a new scenario. Whenever there is a shortage of workers in the local market, or there is a huge demand for workers in a place, the trend of immigrant workers has been observed over the years. For instance, after Hurricane Katrina, the involvement of a huge number of immigrant workers was observed in Louisiana [38]. Sometimes the workers are reported to be skimped on their regular wages and rights [15], and sometimes they are seen to be having issues understanding the instruction due to different languages [38].

Nepal is a diverse country in terms of ethnicity and language. There are 125 ethnic groups in Nepal having around 123 languages [82]. Nepal being a multilingual country, authors thought the involvement of immigrant workers in PDR sites might shade light on some of the issues related to the safety of the workers. One example can be not understanding the instructions in the local language or misinterpreting the meaning of the instruction thus putting themselves into risky situations. Keeping that in mind, workers were asked about their origin and if they belonged to the area where they are working. Three of the workers (Worker-501, Worker-502, and Worker-503) replied negatively and said they were immigrant to that area. They also added that they moved to that area because there was a need of workers and they came looking for jobs. Upon asking about their language and if they were having any difficulty understanding the instructions, Worker501 replied, "I haven't faced such issues till date. As everyone working here speaks Nepali, 
I can clearly understand the instructions from the engineers and contractors," and Worker03 also replied in the similar fashion saying "Nepali" is used so, no case of language issues". When the interviewer brought up the topic of immigrant workers being skimped of their basic rights and discrimination in wages in comparison to local workers around the world, Worker-04 responded "No, not really. We are not discriminated, and the local workers and immigrant workers work together as friends". The other respondents also responded in a similar fashion stating that there is generally no language issue even if the workers are from a different region having a different language. Supervisor-501 answered all the associated questions and said, "Yes I have worked with immigrant people from other region. Recently some of our workers were from the Terai Region but we did not have any issues regarding language. Everyone understands Nepali. And all the workers are paid equally".

Usually, owners and contractors are the stakeholders who hire workers, pay them and interact with them the most. When we asked the owner and the contractors regarding the issues involving immigrant workers, they also responded indifferently. The owner said, "There are immigrant workers in my site. But there is no issue with interacting with them. And all the workers are equally paid. I pay all the workers on the basis of what work they do not on their origin or language". One of the contractor, Contractor-502, himself being an immigrant responded that he had not faced any issues communicating with anyone around him. His response was, "As I am a Newar, I have my own language. But, I do work with any people where I have not faced a language issue. As we have a common language "Nepali." So, there is a very rare case of language issue". But Engineer-502 gave his response in difference to the others. He responded that he had faced some language issues 
while working with the immigrant workers but only if they don't know Nepali. His response was, "Sometimes it is difficult as workers coming from Terai speak only hindi or maithaili." Therefore, when there is at least one common language among the stakeholders, Nepali, they can overcome the issues associated with immigrant workers and their language. But if they only understand other languages such as Hindi or Maithaili, issues might arise regarding the understanding of instructions and the means of communication.

\subsubsection{Safety Training}

The importance of safety training extends beyond a worker's introduction to the job. It helps a worker when his/her job changes or when working conditions change. Without an understanding of safety practices related to his/her job, a worker will be at a higher risk for workplace injury, illness or death. According to OSHA, training is an important tool for informing workers about workplace hazards and controls so they can work more safely and be more productive; needless to mention, to provide workers with a greater understanding of the health and safety.

Usually, all the professionals get some sort of training related to their field of work at some point in their career. Considering that, our questions regarding safety training were very specific. Respondents were asked if they have received any training on safety in their career or prior to joining a PDR site. All four workers responded in the negative that they hadn't received any kind of training prior to starting working on PDR site neither there was any requirement for training. National Society for Earthquake Technology - Nepal (NSET) has been providing training to the masons and construction technicians but none of them on safety issues. One of the engineers, Engineer-504 responded, "Yes. I got training from NRA (Nepal Reconstruction Authority). But not on safety. I was trained on building 
earthquake resistant houses and training the masons," but Supervisor-502 said, "No, I was not given any special training for PDR works. However, we worked together with the Red Cross Society, and I got the basic safety education there". When we asked the workers and supervisors about their opinion on training and whom they think should provide them with the required safety training, Supervisor-503 pointed out that the Municipality and government organizations should provide them with the training and Worker-503 thought the Contractor should be liable for providing them with necessary safety training. When the interviewer brought this to the contractor's attention, the contractor was seemed reluctant about the thoughts of the worker. He said, "No, we do not give any special training to workers. However, I have got basic safety training from Khwopa College a few years ago".

\subsubsection{Safety concerns before and after the earthquake}

Construction workers' health and safety have always been an important matter of focus. Rigorous studies have been done on new methodologies, technologies, and training to enhance the safety at construction sites. However, in Nepal, for some reason, workers' health and safety have not been addressed properly. No significant training on the safety of workers has taken place in Nepal either. Contractor-501, having 30 years of experience in the field, reported that there had not been any significant activity regarding the construction workers health and safety during his career. Upon asking what happens if there is any accident and who is liable for the compensation, he replied, "The contractor and the owner both provide with the medical need when a worker faces any accident." The owner also supported the idea of saying on the same note, "I, being an owner should be responsible for whatever accident happens at my site." 
When the interviewer asked the engineers about the safety concern before, and after the disaster took place, Engineer-504 pointed out a significant point, which may be affecting the safety issues after the disasters. He explained that after the disaster there is a rush to build the houses back. Owners and contractors both want the work to be done quickly and that may put the workers into a situation where they prioritize speed of work over their well-being. He said, "Yes there is actually a rush to finish the work. And you know what, may be that is another reason which makes the PDR sites more risker to work on. Everybody is in a rush to complete the work. And when you rush for something, it's not going to be perfect, and you are exposed to hazards more often." When the interviewer asked the workers if they are being pushed by the owner or contractor to finish the jobs early or ahead of schedule, three of the workers replied in the affirmative. But they said they are also being paid additionally for their extra hour works.

\subsection{Conclusion}

The analysis of these semi-structured interviews we conducted with the Owner, General Contractors, Engineers, Supervisors, and Workers from Bhaktapur revealed the construction workers' safety situation in Bhakapur, Nepal. This analysis showed a picture not only of Bhaktapur but also of Nepal in terms of workers' health and safety. From the discussions we had with different stakeholders of PDR, they presented their different perspective on the same issues. The questionnaires were divided into five categories based on the topic of discussion. Following the main discussion topic, follow up questions were thrown at the participants and in some cases, their perspectives were found to be similar, and they agree to certain issues, for instance, all the respondents agree that PDR is different than regular construction. And they identified some key factors how PDR sites are 
different. Factors such as lack of workers, time constraints, poor management, lack of proper working space, and hazardous debris are some of the main contributors that makes PDR different from regular construction.

Using immigrant workers and skimping them from their basic rights has been reported in several cases all over the world [38]. But our study revealed a different scenario in Bhaktapur, Nepal. The immigrant workers reported to be treated equally as local labors, and in some cases, they even get paid more than the local workers. Despite having different native languages, they did not face any problem communicating with the other stakeholders because of a common national language. The owners and contractors both stood by to say that there is no discrimination between local and immigrant workers irrespective of the circumstances.

The respondents also agreed upon the importance of using personal protective equipment (PPE) and having safety training prior to joining any construction work, especially PDR. The workers and supervisors expressed their concern saying they receive neither any PPE nor any safety training. The stakeholders who are responsible (owner and contractors) for providing PPE and safety training also concurred to the fact that they do not provide any of those to the employees. While according to the Nepal Labour Act 2074 (2017) chapter 12, employers are responsible for providing necessary safety equipment and training to the workers and they are completely responsible for the safety and well-being of the workers. It is worthwhile to mention that the Nepal Labour Act 2074 was passed after the Nepal earthquake 2015. Although passing the act after the earthquake, issues such as workers safety and well-being were not focused on it. Our study reveals a lack of enough PPE usage in Bhaktapur, Nepal. It is also worthwhile to note that there is no specific safety 
training guide or a list and specification of PPE available to be provided to the workers. According to the Nepal Lab our Act 2074, the employers (owners and contractors) are supposed to come up with rules and regulations to ensure the health and safety of the workers based on the nature of the work. Authors believe that a concrete formulation of safety training and guideline for providing safety equipment would definitely help the employers to follow the new Labor Act of Nepal, thus ensuring the safety of the workers.

The previous Labor Act of Nepal did not have any provision of the health and safety of the workers, which reveals why there no attention has been given to the health and safety of the workers. Even after the issuance of the new labor act in Nepal, focus has still not be given to the health and safety issues. The respondents of this study also reflected upon the fact that the safety of the workers was never a concern for the employers before the disaster. Now, after the disaster, though there is a new Labor Act in Nepal, the concern for the safety of the workers remains unchanged. The Government of Nepal and the people's concern is majorly towards the robustness and resilience of the structures after the disaster. However, there is no provision for the safety of the workers during PDR [84]. While the government looks at the bigger picture of creating a more robust and resilient Nepal, we look at the smaller pictures where lives are still at stake on the construction sites during the reconstruction phase. We believe every accident is preventable and every life is worth saving. Paying attention to the workers' health and safety during post-disaster reconstruction is as important as making the structures more resilient. 


\section{CHAPTER 6}

\section{Worker Health and Safety during Post-Disaster Reconstruction: In depth Analysis}

\subsection{Introduction}

As specified earlier, chapter 5 discusses the small scale pilot study conducted in Bhaktapur, Nepal to investigate the safety situation and also to do a feasibility study if a bigger scale and in depth qualitative study is possible with the same context. After analyzing the qualitative data of 14 respondents collected from a secondary source, it was clear that there are issues with construction workers health and safety during post disaster reconstruction phase in Nepal. Keeping that in mind, the second set of data was analyzed to investigate even further. The second set of data was made available to the author by the interviewers from Nepal.

This chapter talks about the qualitative data analysis and findings from the 24 more respondents that were interviewed with a modified and updated set of semi-structured questionnaires. This chapter also represents the different safety factors that were identified during the interviews. Analysis has been done using the software Nvivo (specified in Chapter 3 Methodology). Different analysis such as coding the transcription, creating different nodes based on the safety factors, matrix analysis based on the relationship between demographics and nodes and word cloud query has been done to support and prove the hypothesis of this study. 


\subsection{Methodology}

The methodology adapted in this chapter is similar to the methodology of chapter five. This is also done following a qualitative and exploratory method. The analysis has been done following the second set of data. The interviewers from Nepal modified and extended the questionnaire based on the findings and lacking from the previous pilot study. More associated questions were included to get a better perception of the respondents. Table 10 below shows the type and number of respondents for this sesson of the interview. As specified, two government officials, two general contractors, nine engineers, five supervisors, and six workers were interviewed following the in depth questionnaire.

Table 10: Participants Type and Number for Further Investigation

\begin{tabular}{|cc|}
\hline Participants' Type & No of Participants \\
\hline Government Officials & 2 \\
\hline General Contractor & 2 \\
\hline Engineer & 9 \\
\hline Supervisor & 5 \\
\hline Worker & 6 \\
\hline Total & $\mathbf{2 4}$ \\
\hline
\end{tabular}

The participants were well informed of the target of the study, and it was made sure that there is no repetition of the participants from the previous set of interviews. All 24 participants were unique. The interviews were conducted in Nepali since Nepali is the local language of Nepal. The questionnaire was first formulated in English and consequently translated into Nepali for the ease of conducting interviews. The interviews were recorded using an audio recorder. And then the recordings were translated and transcribed simultaneously in English. All before, all the respondents were given with a unique user 
ID to keep their identity anonymous. The translated transcriptions were then analyzed using different tools from Nvivo and thus providing with different findings.

\subsection{Discussion}

The analysis and findings from the chapter 5 brought up five specific factors that contribute to the health and safety of the construction workers' during post disaster reconstruction phase in Nepal with the context of Nepal earthquake 2015. The factors that are discussed in chapter five are; Difference between Regular Construction and Post Disaster Reconstruction, Use of Personal Protective Equipment (PPE), Involvement of Immigrant Workers, Safety Trainings and Safety Concerns before and after the Disaster. However, among the findings of this chapter, these five factors are also present but representing no new concept or sub factor. Thus from the findings of this chapter, these five factors have been excluded to omit the repetition. This chapter will be presenting factors, unique from the previous analysis and findings, affecting the health and safety of the construction workers during the PDR phase. The safety factors are discussed below.

\subsubsection{Use of Unskilled Workers}

Construction is a labor intensive and one of the most hazardous industries among all [85]. According to BLS, Construction industry is responsible for $12 \%$ of fatal injuries at workplace making it one of the riskiest industries for workers [25]. Construction workers can be divided into three categories based on their required skill set; Unskilled Workers, Semi-skilled Workers and Skilled Workers. Generally, skilled workers are involved in specific works which require skill or decision making the ability to some extent whereas

semi or unskilled workers are involved in works that do not require skill or decision making 
ability. Following a study conducted in Malaysia, where 100 construction accidents were analyzed, it was seen that even semi-skilled and skilled workers were involved in $60 \%$ of the accidents due to the nature and complexity of the work [70]. Another study ranked the use of unskilled workers as the sixth most effecting reason that affects construction safety [47]. During the post disaster reconstruction period, shortage of skilled workers and the use of unskilled workers instead of skilled ones have been identified in the media [50] and in scholarly articles as well [30]. Thus, it is evident if unskilled workers are used instead of skilled workers, construction accidents will take place even more.

Usually, owners and general contractors are the stakeholders that hire construction workers. When we asked the owners and general contractors regarding the issue of hiring unskilled or inexperienced construction workers, they responded positively stating that they do hire unskilled or inexperienced workers upon requirement. General Contractor-602 replied upon asking,

"Yes. We hire people based on our demand. If I have multiple construction sites and I need more people, I hire people irrespective of experience or skill. However, I do try to keep a good balance of experienced and inexperienced workers. You see, I can't run a site with all the inexperienced workers. So, I keep a balance."

When we asked about the risks associated with involvement of unskilled workers, General Contractor-601 agreed with the fact that there are certain risks and potential of accidents with the involvement of unskilled workers. In his words,

"I know there are certain risks when I hire unskilled construction workers. They do not know how to tackle certain situations. But that is how they learn. With time, they get 
experience, and they learn. Often the other experienced people guide them on how to do certain risky works. Or they don't allow them to do risky works. Unskilled workers are mostly given the easy tasks that have minimal risks".

Among the six construction workers that were interviewed for this study, two of them had less than 5 years of experience. And both of them started their work in the PDR site. Upon asking about their perception regarding the risks associated with working in PDR, one of them, Worker-604, indicated that he is ignorant of the risks associated with the works he does and he sometimes gets hurt.

"When the earthquake hit, my father got badly injured. I needed a job to support my family. So I started working in this reconstruction site. I don't know much about the risks. I try to be careful with the works I do. Sometimes I get hurt. But it's not anything major. Once I was trying to remove the rubble from one house, and the pile came down on me, and my legs were hurt."

When we inquired with the government officials regarding the involvement of unskilled or inexperienced workers at the reconstruction sites, they showed some extent of reluctance. They indicated to the fact there is usually a lack of workers when need. And one of them, Government official-601 said that it's not in their jurisdiction to monitor if the hired workers are experienced or not.

"After the 2015 earthquake, we needed a lot of workers to work on the disaster affected areas. Works such as debris clearing, making pathways also repairing the houses. We were not aware if the workers were skilled or not. Even common people also came forward to help. Volunteers from different organizations came forward to help with the 
works. I admit these works are risky and anyone can face serious accident but what else can we do. There was no time to train people or select skilled people."

When we asked the supervisors about the involvement of unskilled workforce in the PDR work, most of them responded in a similar fashion stating that the unskilled workers are more prone to construction hazards in PDR site. Supervisor-603 pointed out the fact that they are the ones who remain mostly close to the workers to observe their works. He said,

"Since my job is to supervise the work that is going on and also to manage the workers, I observe them closely enough. I have seen a huge difference between skilled and unskilled workers in terms of safety. Unskilled or new workers have no idea what they are doing. Even if there is some hazard that can be avoided with common sense, they are ignorant of that. They need proper training before entering a hazardous job site like reconstruction works. There are more vulnerabilities in the reconstruction site that regular construction."

\subsubsection{Mental Health of Workers}

Construction work has been identified to be one of the most stressful work both physically and mentally [86]. The stress increases the possibility and probability of accidents for construction workers at workplaces [87], [88] and when it comes to posting disaster reconstruction works, it becomes more significant. According to a study, $34 \%$ of the world population has gone through a post disaster trauma which leads them to Post Traumatic Stress Disorder (PTSD) [89] and post disaster reconstruction workers are no different to them [44]. PTSD leads to several health problems including cardiovascular 
diseases, respiratory diseases, chronic pain conditions, gastrointestinal illnesses, cancer and suicidal attempts [45]. Not only the stress of the construction related job but also the effect of the disasters put the workers in a difficult position to deal with everything at a time. Upon asking, Worker-606 who is a mother of two, expressed her concern while working at the PDR site. She explicitly said,

"I am always worried about my kids while I am at work. I have seen the disaster. It's bad. I am thankful to god that I and my family is safe from the disaster. But I keep worrying about their safety."

This statement signified the fact that being under stress all the time at the workplace, may lead her to be ignorant of construction hazards and lead to accidents. Worker-01 and worker-03 also showed their concern in the similar fashion saying that immediately after the disaster they were always terrified of the earthquake but still had to keep working. When we brought up this issue to the supervisors, since they are the ones being in touch with the workers almost all the time, they replied in the positive that they have also witnessed some cases where the workers were reluctant to their job. Supervisor-602 said,

"I have seen people always being sad and depressed at my site. One of the workers that were working on my site had lost his house due to the earthquake. I didn't see him smiling in a few months."

Engineer-606 reported to the fact in the same manner although he has not faced anyone like this. But he thinks after the disaster everyone was in a shock, and it took a long time to recover from that. He said, 
"We all were in a shock. We were afraid of sleeping in our houses for a long time. Wherever we were, we were always worried and scared. I believe the workers that have to keep working day and night in the disaster affected areas are also the same. And yes, getting exposed to hazards and accidents are more common in these circumstances."

Engineer-601 also mentioned about the stress and challenges that he used to get from the work place. He remembered his time just after the earthquake how he used to sleep in tents instead of houses, and she also mentioned due to everything happening around her she got depressed very often. She said,

"There were many challenges when I was away from my family; it was the time after the earthquake that I was working in Bhaktapur. There were no proper houses as every house were devastated. So, I had no options except sleeping in tents \& I felt so insecure at that time as a girl \& miss my home. There was a kind of mental torture. Obviously, yes I got depressed. There were many torture \& challenges dealing with those who are affected by disasters.

Upon asking about the same issue to the general contractors if they pay attention to the fact that the workers get depressed due to post disaster trauma, general contractor-601 replied,

"We all are under stress in such situations. I have seen so many disturbing scenarios while working that it disturbs me. I have even found dead bodies under the rubbles. It is disturbing, and I couldn't sleep at nights. I think the government should take some initiatives to help those who are suffering from this kind of distress." 
The discussion here clearly shows that in a post disaster situation, workers are usually under a lot of mental pressure and post disaster trauma that might lead them to potential hazards. The government should be taking necessary steps to help these people so that can work safety and freely in their workplace. Further study can be and should be done to investigate how these issues with mental health can be dealt with in PDR sites.

\subsubsection{High Inflow of Money}

Disasters affect human life and surroundings in many ways. Among all other, loss of housing is one of the major losses people have to face because of disasters. Every year around 14 million people become homeless due to disasters all around the world [90]. In response to the disasters and loss of homes, many international organizations such as Red Cross and World Bank come forward with funds to help the nations to overcome. More than $50 \%$ of the World Bank's PDR loans are used for housing reconstruction in affected areas [91].

Upon asking if the high inflow of money has any diverse on the health and safety of the construction workers, Engineers and General Contractors replied in the positive. Engineer-609 said,

"I know there are lots of funds coming from different organizations. But I don't think those funds are used for the purpose of increasing the safety of the workers. Mostly the funds are used for restoration and rebuilding the structures. But I believe at least some of the funds should be dedicated for the purpose of safety training and PPEs."

On the same context, general contractor-601 said, 
"What I think is, the funds don't even reach to the field level. Even if there is any fund for the safety and wellbeing of the workers, you know the corruption in the government level. Due to the high level of corruption, most of the money is gone before implementing."

Supervisor-605 brought up a very interesting point about the high inflow of money that since the owners were receiving financial aid and they want their houses rebuilt soon, they urge the GC and workers to work faster. This urgency may expose the workers to construction hazards more. In his words,

"You see; NRA was giving the affected house owner some financial aid. And they wanted their houses to be rebuilt as soon as possible. That's why they are always in a hurry and want to build or repair their house ahead of time. And when you are rushing for any kind of work, it is going to expose you to certain hazards."

Although having enough funds for the reconstruction process, accelerates the recovery process, it has its negative sides as well. Having funds in hand, although not enough to complete the job, creates a tendency of a rush to finish the works which might expose workers to potential danger. Also, if the country and government has significant corruption in the system, the transparent flow and distribution of the money are not ensured. When the money could be used for training purpose or enhancing safety in the job site, it goes somewhere else keeping the jobsite and workers with potential hazards that could have been tackled with.

\subsubsection{Debris Management}

One of the main components of the PDR process is the removal and management of debris that takes place after natural disasters. Proper and early removal of debris is 
important after the disaster, but at the same time, it is a risky job according to many scholars. According to FEMA (2007), there are nine types of debris that are produced during different types disaster namely Vegetative, Construction \& Demolition, Hazardous Waste, White Goods, Soil, Mud \& Sand, Vehicles and Vessels, Putrescent Debris, Infectious Waste, and Chemical Debris and each of them carries their own risks and potentiality of hazards to human health. The presence of hazardous and contagious debris makes the PDR sites more vulnerable in terms of health and safety [69]. Centers for Disease Control and Prevention reports that increasing injury trends due to identified illness cluster and unconfirmed illnesses have been observed among the workers involved in PDR [43] which proves that Construction Workers at PDR sites are exposed to illnesses, both identified and unidentified.

Worker-601 and Worker-604 expressed their concerns regarding the risks associated with debris removal and management since they had worked on debris removal projects after the disasters. Worker-601 said,

"It was a very bad and damaging earthquake. There were lots of lots of debris here and there. We had to clean all the rubbles and debris to make clear pathways and to work on different structures. And I can tell you; it is not safe to work in. You don't know which pile of debris is loose and when it is going to come down at you. You might step on a wrong place and might caught in between objects. It is a very risky job."

While worker-601 was talking about the risks of caught in between or get hurt by the debris, worker-604 brought up another aspect. He mentioned about possible diseases that can be caused by rotten foods and dead bodies. He said, 
"All the houses were destroyed in the area I was working. People were living in tents in open fields. When we were working on the damaged house to remove debris, we got a really bad smell of rotten foods from their fridges and kitchens. We had to clean those up as well. We didn't know if those things were going to make up sick or not, but we had to work anyways."

We asked the stakeholders who are responsible for hiring and appointing the workers if they provide any kind of special training to these workers regarding debris management since it possesses a potential threat to health, they all replied in the negative. The mentioned the lack of time, opportunity and knowledge to provide such training or even information to the workers. Government official-602 said,

"We don't have such opportunities to train people about the debris management. It is just a work that they got to do. Moreover, we don't have the right personnel who can train these workers".

\subsubsection{Chemical Contamination and Health Issues}

Along with the debris management issues, one more important issue arises up which are the potential risk of chemical contamination and health issues related to that contamination. Previous studies have mentioned that there are certain cases where construction workers were diagnosed with a respiratory illness, skin disease and other unidentified sickness [92]. Upon asking about their perception regarding the potential chemical hazard during PDR works, Engineer-608 said,

"Everything was so devastated after the earthquake; only God knows what is there under the rubble. There might be different types of chemicals or infected water clogged 
somewhere. All these things are dangerous to human health. But I don't see any way to get rid of these. We had to work among these risks and issues."

When we checked with the workers working with the debris, and in post disaster reconstruction work site, they seemed to have no specific knowledge about the chemical contamination or health issues related to these chemicals. However, one of them, worker602, said that sometimes he felt difficulty in breathing after working long hours in PDR site since there were lots of dust in the air and he didn't use any mask to protect himself. He mentioned,

"There were lots of dust in the air. I didn't care about using a mask while working in that condition. At nights, I used to cough a lot, and I have had a hard time breathing properly. I think that is because of those dusty areas where I used to work."

Upon asking the general contractor if they were aware of this situation, they replied in a fashion that it is not a big deal for the workers working in construction sites. General contractor-602 said,

“...they are used to working in this kind of conditions. Even if we ask them to wear masks or protect their face from it, they usually don't follow. They do whatever they want, and we don't really bother them."

\subsubsection{Participation of Community People}

During the post disaster reconstruction phase, there is usually a huge lack of construction workers to initiate the reconstruction process. One of the ways to meet this deficiency in a disaster-affected area is the participation of local community people in the 
reconstruction process. Though participation of community people in PDR has always been encouraged by the governments, NGOs and scholars, it has its own risks and challenges. Davidson, Johnson, Lizarralde, Dikmen, \& Sliwinski, (2007) expressed their concern regarding the little knowledge and applicability of this solution to the shortage of workers during the PDR phase. Community people without the required knowledge or skill of construction are always vulnerable and exposed to hazards. It is also worthwhile to mention that most of these community people who participate in reconstruction works are also disaster survivors as well. Working at the PDR sites, confronting their own devastated homes and the dead bodies of their own people, often lead them to Post-Traumatic Stress Disorder (PTSD) and Depression (as mentioned in the Mental Health section). It has also been observed that PTSD often leads the sufferer to suicidal attempts [44].

We brought this issue up to all our respondents. Both the government officials encouraged the participation of local community people during the reconstruction project. They indicated that they could use as many help as possible to accelerate the reconstruction process. However, upon asking about the safety issues, Government official-601 replied, "Construction work is always risky. If you don't have enough experience, you are more exposed to hazards. That is true for these people as well. But here, I have seen so many times, that the owners do their own small repair and other works by themselves. They want to save money and don't hire professionals. It is not safe, but they keep doing it anyways. So why not now?"

Engineer-607 shared her experience regarding the involvement of community people in reconstruction works. He described how a woman tripped over during the work going 
on because she didn't have proper cloths neither she knew she should be more careful while being in the active construction zone.

"The owner of the house was trying to help us by moving some tools from one point to another. She was wearing a traditional dress and didn't have any safety equipment. She was walking reluctantly, and suddenly her cloth got stuck under some brick, and she got unbalanced and tripped over. She hurt her shoulder and back."

Engineer-601 also responded in a similar fashion thus strictly discouraging the involvement of community people for the sake of their own safety. He said,

"I have seen community involvement in reconstruction work. Both government \& community work together. But obviously, it's not safe for the common people to get involved in reconstruction works. As I said earlier, construction work is itself very dangerous let alone reconstruction work. So I believe the involvement of common people to the reconstruction sites and work should be limited to some extent. And safety measures should be taken for them as well."

From the interviews, it also came up that the people not only want to help in the work, but they also want to help the workers who are trying to restore their houses. Worker-605 expressed his gratitude to the fact that the community people around him, where he was working, were very kind and helpful. But he also pointed out a fact that if they start trying to help in the work, it might slow down the work since common people don't know what and how to do such things. 
“...they used to provide us with food and water all the time. And we also tried our best to complete their houses fast. There was a good mutual understanding among us. But as community people don't have any idea about the construction work, I think it slows down the work even more."

On the other hand, supervisor-605 claimed that since the reconstruction work is even riskier than the regular construction, it should only be done by the experienced and professional people. In his words,

"I have seen community involvement in reconstruction work. But, people participate in their own building construction work which is not safe. I think the construction works should only be done by the skilled and experienced people."

Construction work has been identified to be one of the most stressful work both physically and mentally. The stress and trauma increase the possibility and probability of accidents for construction workers at workplaces, and when it comes to PDR works, it becomes more significant. So participation of the community people, having no experience or skills, is rather more dangerous. And instead of accelerating the progress, sometimes it slows the work down.

\subsubsection{Building Back Faster Syndrome}

Big natural disasters, such as the Nepal earthquake 2015, usually make a huge impact on the community in terms of structural and infrastructural damage. The whole community gets affected badly because of these kinds of disasters. People get homeless and live in open fields under tents. As a result, the government and construction companies urge to build as many structures as early as possible [49] resulting in 'Building Back Faster'

syndrome. Because of that, they compromise with the construction workers' skills and 
expertise thus overall health and safety. With less skilled work force, they became more exposed to construction hazards. This sort of scenario has been observed in a few studies as well [14] [50] [52].

When we inquired about to the construction workers in they were rushed by their employers to finish the work, all of them responded in the positive. They agreed to the fact that during working in PDR projects, they were always in a rush by their employer to finish the work as soon as possible. Upon asking if this put any effect on their safety, Worker602 emphasized on the fact that it is a big issue in terms of safety. He said,

"Whatever is done in a rush, it cannot be done perfectly. We were always pushed by our supervisors and contractors finish the work early and even work overtime. This puts a lot of pressure on us. As it's not safe for us, it is also not safe for the future since the reconstruction work might have some fault."

Being the employer, General contractor-602 also agreed to the fact that they urge the workers to finish work early, but he also mentioned that they never ask the workers to compromise with safety.

"We never ask anyone to compromise with the safety. Life is the most important thing for all of us. However, we also want to finish the work as early as possible. We have pressure on our head from the owners and sometimes from the government authorities."

\subsection{Conclusion}

The analysis of this in depth semi structured questionnaire interview revealed the construction workers' health and safety situation even further from the pilot study (refer to 
chapter 5). This analysis was done to explore the health and safety issue of the construction workers during the post disaster reconstruction phase in Nepal. The questionnaire was designed in such a way that the respondents are encouraged to open up more and share their personal experience and perspective while working on the reconstruction sites. Having a good mix of different stakeholders from PDR such as General Contractors, Government Officials, Engineers, Supervisors, and Construction Workers gave this study a good all round perspective on the same issue. Besides having a good variety of stakeholders, respondents represented different age, years of experience and gender. Nine of the total respondents were female which showed that in Nepal female employment is not neglected in the construction industry. Whereas in many countries, female participation in construction is very limited. Figure 7 below graphically represents a knowledge gap in the area of post disaster reconstruction in terms of workers' health and safety, and it also enlists the factors that are identified from this study. 


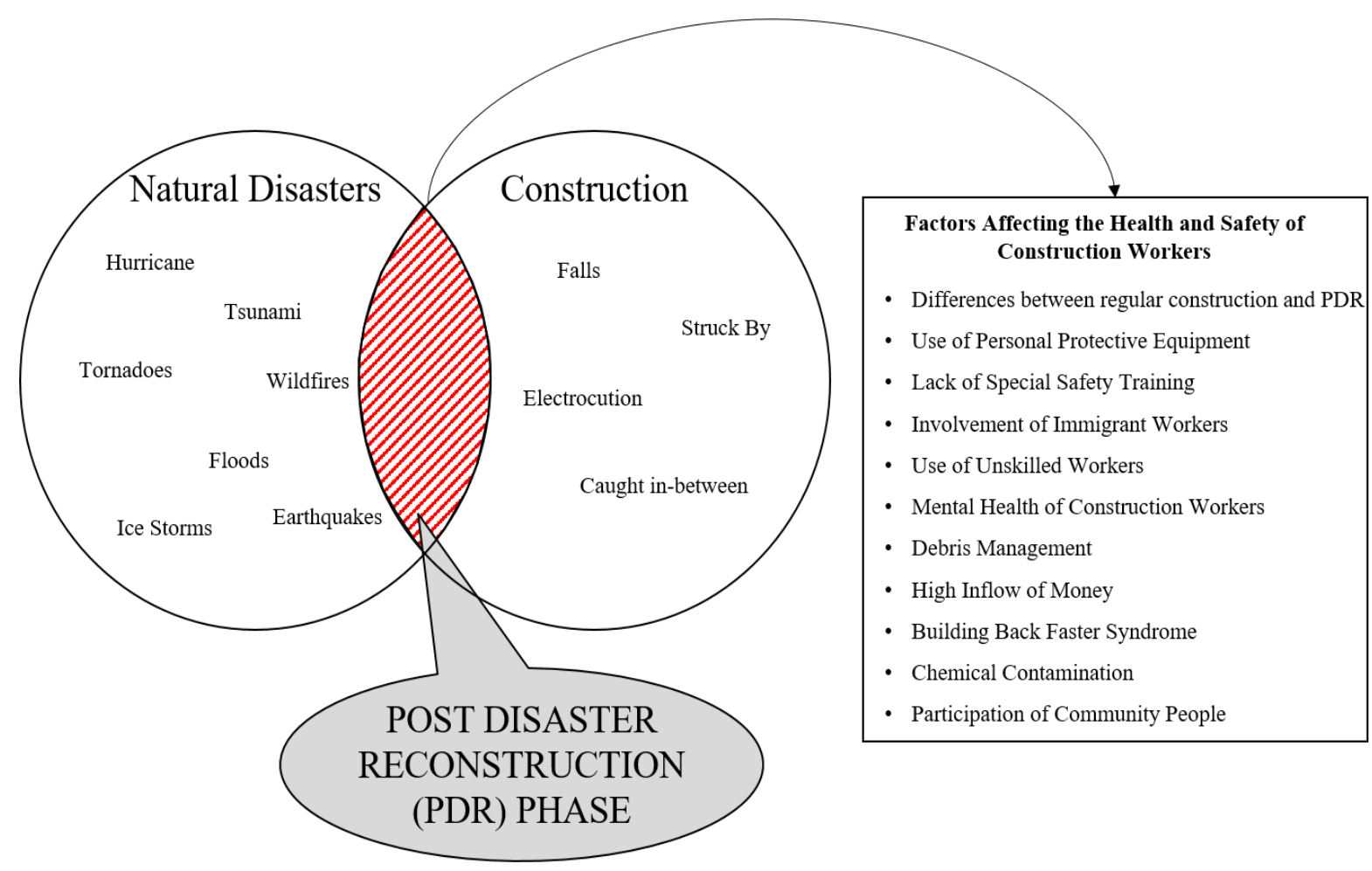

Figure 7: Knowledge Gap and Factors

The analysis of this study revealed several factors such as Use of Unskilled Workers, Mental Health Issues, High Inflow of Funds, Debris Management, Chemical Contamination, Participation of Community People and Building Back Faster Syndrome are some of the vital factors that contribute to health and safety of the construction workers during post disaster reconstruction phase. Almost all the respondents agreed to the fact that there is usually a lack of skilled construction workers during the PDR phase, so unskilled or inexperienced workers are hired for the work. Although it exposes the unskilled workers to construction hazards, even more, people are still doing it in Nepal. One of the reasons for this might be the financial need. Many families got severely affected by the earthquake, and they needed immediate work to support their household. So in spite of being exposed to hazards, they work willingly. 
Disaster survivors are the main victim of post disaster trauma. Many of the workers who work on PDR sites are also survivors from the disasters. They expressed their concern regarding the mental pressure they had to face during and after the disaster. This study revealed the fact that these conditions are not suitable for works specially construction works. Some of the workers are also immigrant where we already know how immigrant workers are facing problems in the PDR phase (refer to chapter 5). Some of the respondents indicated to the fact the government should come forward to play a role and helping the disaster survivors to come round from the trauma. Post disaster trauma and stress due to the nature of construction works often lead the workers to depression. Although no case of suicidal attempts was noted during the interviews, the study says depression can lead people to suicidal attempts.

High inflow of money and building back faster syndrome are very closely related to each other. After Nepal was hit by the earthquake in 2015, lots of international organizations and other nations spread their helping hands in forms of financial aid. So it seemed that there was a lot of funds available for initiating different types of the recovery process. That issue urged the process of rebuilding faster. Many of the respondents indicated to this fact there was always a rush to complete the work faster than schedule. This led them to compromise with the quality of the work and most importantly compromising with the safety situation.

While debris management is one of the first tasks that need to be done after a disaster, there are certain issues related to the health and safety of the construction workers that need to be attended seriously. Through the study, it was revealed that no worker is aware of what 
kind of hazards they are exposed to due to the involvement in debris removal works. They don't even get proper PPE to work in these kinds of situation. Some workers also reported that they faced some kind of accident due to the debris. Chemical contamination and disease are two more big factors came up through the study. While working on debris removal and management, few workers complained about having several health issues such as respiratory problem and unknown illness. Most importantly, even the government officials agreed that they are reluctant to these kinds of issues and they don't have enough knowledge to train people to be aware of these situations. Moreover, priority should also be given to the training which may improve the health and safety condition of the construction workers during the post disaster reconstruction in Nepal.

Participation of community people in the reconstruction works is mostly encouraged by the Government, NGOs, and scholars as well. The perspective is that the participation of the community people accelerates the recovery process. But unfortunately, the safety aspect has always been neglected in this case. Our study revealed that the participation of the community people is not only risky for their own safety but sometimes there inexperienced people creates unwanted hazards for the construction workers as well. Moreover, when these people try to help and try to do something that they do not know how to, they make the process slow. Few of the workers who had experience with this kind of situation, they reported about the delay and lag due to the participation of the common people to the reconstruction works.

This study also revealed some other important issues that may not contribute to the health and safety of the construction workers, but the author believed these issues are also 
as important as any. The workers were asked about their process of compensation when they face any kind of unfortunate accidents. It was a surprising finding that these workers are not getting any sort of compensation if they get on the jobsite. Even the employers also agreed to the issue that workers are "On their own" in this case. They don't even have any health insurance policy that might cover up the damage and loss they receive at the work place. In short, there is no security for them. Upon inquiring it was also explored that there is no government authority where accidents are reported. There is no governmental agency that would look after the rights of the workers. In the United States, OSHA plays a very vital role in terms of workers' health, safety, and rights. Such an agency is necessary for a country like Nepal where they do not even have any safety provision in their Labor Act (refer to chapter 5).

The findings from this study reveal the different factors that affect the health and safety of the construction workers during the post disaster reconstruction phase. PDR exposes the construction workers to even the more hazardous environment, and there are certain issues that people don't even care. But these minor issues can lead to serious damage and fatality in construction sites. The findings of this study may help the policy makers to design and implement a better recovery plan from a disaster. Following these findings, training seasons can be designed to make the workplace safer for construction workers during the post disaster reconstruction phase.

Also, there might be implications for debris management, counseling, etc. You might want to talk about those as well. 


\section{Conclusion}

\subsection{Summary of the Study}

The purpose of this study was to identify a knowledge gap in the literature of post disaster reconstruction phase in terms of construction workers' health and safety. A rigorous systematic literature review in chapter 4 revealed that there is a gap of knowledge in the literature of post disaster reconstruction in terms of workers' health and safety. Chapter 4 also revealed the different themes of research that have been done from the year 2000 to 2018 with the context of PDR. However, no significant study has been done on health and safety until now.

The identification of a knowledge gap led this study to data collection for further investigation. For this study, the qualitative and exploratory method was adopted since there is no prior data or articles available in this context. For the data collection, Nepal was selected as a case study since Nepal is undergoing the reconstruction phase after the 2015 earthquake. In Nepal, several cities and areas were devastated due to the earthquake. One such place is Bhaktapur. All the data are collected from a secondary source with the help of Khwopa Engineering College in Nepal. Individuals from the college conducted the interviews in Bhaktapur since the reconstruction works are going on in full swing. Interviews were conducted in two steps, and so the data was sourced by the author in two steps as well. At first, a small scale pilot study has been conducted (chapter 5) using the first set of secondary data to find out the feasibility of bigger scale study and also to find out the preliminary factors that affect the health and safety of the construction workers. 
The pilot study was a success and revealed several very important factors such the difference between regular construction and PDR, use of PPE in PDR, Involvement of Immigrant Workers, Safety Trainings and Safety Concerns before and after the Disaster.

With the preliminary results, the second set of secondary data was used to investigate even further. This set of data contained in depth interviews with new respondents to find out even more factors pertaining to the health and safety of the construction workers during PDR (chapter 6). This study followed the same methodology just as before, but this time the target was to explore the other factors that have the potential to contribute to the health and safety of the workers. The analysis from this study explored other factors such Use of Unskilled Workers and reasons behind it, Mental Health Issues of Workers during PDR, High inflow of Money in the form of financial aid and Building Back Faster syndrome, Debris Management and Chemical Contaminations and diseases related to the contaminations and the Participation of Community People in the reconstruction works.

\subsection{Contribution}

This study formulated the definition of post disaster reconstruction phase since no concrete definitions were found in the literature. However, the definition that has been formulated is with the context of the construction works taking place after the disaster. Future research related to the same context of this study might be able to use this definition.

One of the main contributions of this study is the identification of a knowledge gap in the literature of post disaster reconstruction through a systematic literature review. The process also identified several other themes of research that have been done over the years with the context of post disaster reconstruction. 
Finally, this study investigated and revealed several factors that are unique to regular construction and contribute to the health and safety condition of the construction workers during post disaster reconstruction phase. Proper implementation of this study, may help save lives at the PDR phase. This study will help the policy makers to design the recovery process even more effectively thus making the workplace safer for the construction workers.

\subsection{Limitation of the Study}

There are several potential limitations to this study. All the data were collected from secondary sources. These secondary sourced data were not solely generated for this study. Moreover, these data represent the views of a few individuals at a specific time and place. Limited qualitative data are not usually generalizable to larger populations [93]. Additional limitations of the study include uneven respondents from alternative perspectives, possible errors of translation from Nepali to English, lack of verbal cues for interpretation, possible lingual and cultural misinterpretation, and unreflected bias of the interpreter on the results. Moreover, since this study is based on the case of Nepal earthquake 2015, the findings cannot be generalized. Variation in safety factors may be reflected for different types of disasters and for a different geographical area.

\subsection{Future Studies}

Since this study and the findings cannot be generalized for all types of disasters and geographical area, more studies need to be done with the context of different disasters in different places. Further study will help to establish or to disprove the factors that have been identified in this study. This study also revealed some issues that may not be 
contributing to the safety issues but possessed the potential for further study. One such factor is the lack of governmental authority in Nepal which might work for the health, safety, and rights of the workers in Nepal.

This qualitative study gives a good platform for further quantitative analysis of the safety factors. A bigger scale quantitative survey can be done to rank the factors in terms of their capability to contribute to the health and safety of the construction workers during post disaster reconstruction phase. Finally, a comparison can be done between the health and safety status of the construction workers in developing and developed countries. Such a comparison will give a good picture of the differences in safety status of construction workers in different socio economic condition.

\subsection{Acknowledgement}

I would like to thank Ms. Kiran Shilpakar, Ms. Anjana Karki, Mr. Pramesh Bhaila, Mr. Shivahari Pokhrel, and Mr. Shairan Twanabasu, undergraduate students of the Department of Civil Engineering at Khwopa Engineering College for formulating the questionnaire and conducting the interviews with the local participants and also for transcribing the interviews. I would also like to thank Mr. Jeetendra Prajapati, Assistant Professor, Department of Civil Engineering at Khwopa Engineering College for supervising the interviews and giving the author full access to the data set for analysis. 
References

[1] UNISDR, “The Human Costs of Weather Related Disasters," 2015.

[2] Centre for Research on the Epidemiology of Disasters (CRED), "Natural Disasters $2017,, 2017$.

[3] USGS, “U.S. Geological Survey: Natural Hazards,” 2018.

[4] UNISDR, "Press release: EMBARGO 11.00 CET," 2018.

[5] D. Guha-Sapir, D. Hargitt, and P. Hoyois, THIRTY YEARS OF NATURAL DISASTERS 1974-2003: THE NUMBERS. 2004.

[6] Piers Blaikie, Terry Cannon, Ian Davis, and Ben Wisner, At Risk: Natural Hazards, People's Vulnerability, and Disasters. 2004.

[7] E. L. Quarantelli, "Disaster studies: An analysis of the social historical factors affecting the development of research in the area," Int. J. Mass Emerg. Disasters, vol. 5, no. 3, pp. 285-310, 1987.

[8] J. Le Masurier, J. O. B. Rotimi, and S. Wilkinson, "A Comparison Between Routine Construction And Post-Disaster Reconstruction With Case Studies From New Zealand," in 22nd Annual ARCOM Conference, 4-6 September 2006, Birmingham, UK, 2006, vol. 2, no. September, pp. 523-530.

[9] M. K. Lindell, "Recovery and Reconstruction after Disaster," in Federal Emergency Management Agency Emergency Management Institute, 2017.

[10] P. R. Berke, J. Kartez, and D. Wenger, "Recovery after Disaster: Achieving Sustainable Development, Mitigation and Equity," Disasters, vol. 17, no. 2, pp. 93-109, 1993.

[11] H. Yi and J. Yang, "Research trends of post disaster reconstruction: The past and the future," Habitat Int., vol. 42, pp. 21-29, 2014.

[12] S. J. Halvorson, J. Parker, and H. G. Researcher, "In the aftermath of the Qa'yamat: the Kashmir earthquake disaster in northern Pakistan,” Disasters, 2010.

[13] T. Lloyd-Jones, M. Theis, R. Kalra, B. Mulyawan, Royal Institution of Chartered Surveyors., and University of Westminster. Max Locke Centre., Mind the gap! : post-disaster reconstruction and the transition from humanitarian relief. RICS, 2006. 
[14] J. Kennedy, J. Ashmore, E. Babister, and I. Kelman, "The meaning of 'build back better': Evidence From post-tsunami Aceh and Sri Lanka," J. Contingencies Cris. Manag., vol. 16, no. 1, pp. 24-36, 2008.

[15] M. Lyons, "Building Back Better: The Large-Scale Impact of Small-Scale Approaches to Reconstruction," World Dev., vol. 37, no. 2, pp. 385-398, 2009.

[16] J. Lewis, "Housing construction in earthquake-prone places: Perspectives, priorities and projections for development," Aust. J. Emerg. Manag., vol. 18, no. 2, 2003.

[17] UNISDR, Living with risk. A global review of disaster reduction initiatives. Preliminary version. United Nations International Strategy for Disaster Reduction, 2002.

[18] IPCC, Climate Change 2014: Mitigation of Climate Change. Summary for Policymakers and Technical Summary. 2014.

[19] I. Blanchi, "1.3 Understanding Post-disaster Recovery Processes: Is There Space for Learning and Experimentation?," ISR-Forschungsberichte, vol. 47, pp. 33-46, 2018.

[20] D. Amaratunga and R. Haigh, Post-disaster reconstruction of the built environment : rebuilding for resilience. Wiley-Blackwell, 2011.

[21] A. Asan and Z. A. Akasah, "Developing an Accident Causation Model for Accident Prevention at Building Construction Sites," in InCIEC 2014, Singapore: Springer Singapore, 2015, pp. 273-285.

[22] A. Ade Bilau and E. Witt, "An analysis of issues for the management of postdisaster housing reconstruction," Int. J. Strateg. Prop. Manag., vol. 20, no. 3, pp. 265-276, 2016.

[23] K. R. Grosskopf, "Post-disaster recovery and reconstruction safety training," Int. J. Disaster Resil. Built Environ., vol. 1, no. 3, pp. 322-333, 2010.

[24] E. Sawacha, S. Naoum, and D. Fong, "Factors affecting safety performance on construction sites Factors affecting safety performance on construction sites," Int. J. Proj. Manag., vol. 17, no. 5, pp. 309-315, 1999.

[25] US Bureau of Labor Statistics, "Fatal occupational injuries by selected characteristics, 2003-2016,” 2016.

[26] OSHA, "Commonly Used Statistics | Occupational Safety and Health Administration," Occupational Safety and Health Administration, 2016. [Online]. Available: https://www.osha.gov/oshstats/commonstats.html. [Accessed: 08-Oct2018]. 
[27] T. Umar and C. Egbu, "Causes of construction accidents in Oman," Middle East J. Manag., vol. 5, no. 1, p. 21, 2018.

[28] O. S. Williams, R. Adul Hamid, and M. S. Misnan, "Accident Causal Factors on the Building Construction Sites: A Review," Int. J. Built Environ. Sustain., vol. 5, no. 1, pp. 78-92, 2018.

[29] C. Boano and M. García, "Lost in translation? The challenges of an equitable postdisaster reconstruction process: Lessons from Chile," Environ. Hazards, vol. 10, no. 3-4, pp. 293-309, Dec. 2011.

[30] C. S. Hayles, "An examination of decision making in post disaster housing reconstruction," Int. J. Disaster Resil. Built Environ., vol. 1, no. 1, pp. 103-122, 2010.

[31] Z. Sadiqi, " Wardak, V. Coffey, and B. Trigunarsyah, "Rebuilding Housing after a Disaster: Factors for Failure," 2012.

[32] D. Ismail, T. A Majid, R. Roosli, and S. A. Hj Noorazam, "A REVIEW OF PROJECT MANAGEMENT FOR POST-DISASTER RECONSTRUCTION PROJECT : FROM INTERNATIONAL NGOs ( INGOs )," Res. Civ. Environ. Eng., vol. 2, no. 04, pp. 199-215, 2014.

[33] H. Yi and J. Yang, "Research trends of post disaster reconstruction: The past and the future," Habitat Int., vol. 42, pp. 21-29, 2014.

[34] W. A. Imilan, X. Fuster, and P. Vergara, "Post-disaster reconstruction without citizens and their social capital in Llico, Chile," Environ. Urban., vol. 27, no. 1, pp. 317-326, 2015.

[35] J. Kennedy, J. Ashmore, E. Babister, and I. Kelman, "Post-tsunami transitional settlement and shelter: field experience from Aceh and Sri Lanka," Humanitarian Exchange, vol. 44, no. 37, pp. 13-15, 2007.

[36] F. Steinberg, "Housing reconstruction and rehabilitation in Aceh and Nias, Indonesia-Rebuilding lives," Habitat Int., vol. 31, no. 1, pp. 150-166, 2007.

[37] K. N. Kim and J. ho Choi, "Breaking the vicious cycle of flood disasters: Goals of project management in post-disaster rebuild projects," Int. J. Proj. Manag., vol. 31, no. 1, pp. 147-160, 2013.

[38] L. E. Fletcher, P. Pham, E. Stover, and P. Vinck, "Rebuilding after Katrina: A Population-Based Study of Labor and Human Rights in New Orleans," 2006.

[39] K. R. Grosskopf and J. Hinze, "Worker safety training for disaster clean-up and reconstruction activities," in Evolution of and Directions in Construction Safety and Health, 2008, pp. 266-286. 
[40] A. A. Bilau, E. Witt, and I. Lill, "A Framework for Managing Post-disaster Housing Reconstruction," in 8th Nordic Conference on Construction Economics and Organization, 2015, vol. 21, no. 15, pp. 313-320.

[41] S. Barakat, "Housing reconstruction after conflict and disaster," Humanit. Pract. Netw., vol. 44, no. 43, pp. 1-37, 2003.

[42] A. Opdyke, Aaron, Javernick-Will, "Resilient and Sustainable Infrastructure Systems : The Role of Coordination, Stakeholder Participation, and Training in Post - Disaster Reconstruction," in Enginering project organization conference, 2014, no. July.

[43] CDC, "Morbidity and Mortality Weekly Report," 2006.

[44] X. L. Wang, C. L. W. Chan, Z. B. Shi, and B. Wang, "Mental health risks in the local workforce engaged in disaster relief and reconstruction," Qual. Health Res., vol. 23, no. 2, pp. 207-217, 2013.

[45] J. Sareen, B. J. Cox, M. B. Stein, T. O. Afifi, C. Fleet, and G. J. G. Asmundson, "Physical and Mental Comorbidity, Disability, and Suicidal Behavior Associated With Posttraumatic Stress Disorder in a Large Community Sample," Psychosom. Med., vol. 69, no. 3, pp. 242-248, Apr. 2007.

[46] O. A. Jannadi and M. S. Bu-Khamsin, "Safety factors considered by industrial contractors in Saudi Arabia," Build. Environ., vol. 37, no. 5, pp. 539-547, 2002.

[47] C. M. Tam, S. X. Zeng, and Z. M. Deng, "Identifying elements of poor construction safety management in China," Saf. Sci., vol. 42, no. 7, pp. 569-586, 2004.

[48] United Nations, "REPORT OF THE UNITED NATIONS IN HAITI 2010,” 2010.

[49] United Nations, "In Nepal, senior UN official warns 'clock is ticking' for earthquake relief efforts | UN News," 2015. [Online]. Available: https://news.un.org/en/story/2015/05/497712-nepal-senior-un-official-warnsclock-ticking-earthquake-relief-efforts\#.VUfEByzhWeI. [Accessed: 25-Mar2018].

[50] The Himalayan Times, "Shortage of skilled workers affects reconstruction work," 2017, 07-Jan-2017. [Online]. Available:

https://thehimalayantimes.com/nepal/shortage-of-skilled-workers-affectsreconstruction-work/. [Accessed: 25-Jun-2018].

[51] Aljazeera, "Nepal's earthquake disaster: Two years and \$4.1bn later |Nepal |Al Jazeera," 2017. [Online]. Available:

https://www.aljazeera.com/indepth/opinion/2017/04/nepal-earthquake-disasteryears-41bn-170412110550808.html. [Accessed: 25-Mar-2018]. 
[52] GFDRR, "Haiti Earthquake 2010: Recovery from a Mega Disaster," Recover. Framew. Case Study August 2014, no. August, 2014.

[53] The Washington Post, "Haiti earthquake: Send in the reinforcements [updated]," 2010. [Online]. Available:

http://voices.washingtonpost.com/achenblog/2010/01/haiti_earthquake_predicted.h tml. [Accessed: 25-Mar-2018].

[54] United States Consumer Product Safety Commission (CPSC), “'Deck the Halls' Safely: CPSC Estimates More Than 15,000 Holiday Decorating Injuries During November and December|CPSC.gov," 2013. [Online]. Available: https://www.cpsc.gov/content/“deck-the-halls"-safely-cpsc-estimates-more-than15000-holiday-decorating-injuries-during. [Accessed: 31-May-2018].

[55] C. H. Davidson, C. Johnson, G. Lizarralde, N. Dikmen, and A. Sliwinski, "Truths and myths about community participation in post-disaster housing projects," Habitat Int., vol. 31, pp. 100-115, 2007.

[56] D. Moher et al., "Preferred reporting items for systematic review and metaanalysis protocols ( PRISMA-P ) 2015 statement," pp. 1-9, 2015.

[57] K. Shafique and C. M. J. Warren, "Stakeholders and their significance in post natural disaster reconstruction projects: A systematic review of the literature," Asian Soc. Sci., vol. 12, no. 10, pp. 1-17, 2016.

[58] D. Denyer, David; Tranfield, "Producing a systematic review," Sage Handb. Organ. Res. methods, no. D. A. Buchanan, A. Bryman (Eds.), pp. 671-689, 2009.

[59] P. Younger, "Using Google Scholar to conduct a literature search," Nurs. Stand., vol. 24, no. 45, pp. 40-46, Jul. 2010.

[60] E. Smith, Using Secondary Data in Educational and Social Research. 2008.

[61] E. Drever, Using semi-structured interviews in small-scale research : a teacher's guide. SCRE, 1995.

[62] J. A. Maxwell, Qualitative research design : an interactive approach. SAGE Publications, 2013.

[63] M. Q. Patton, "Two Decades of Developments in Qualitative Inquiry," Qual. Soc. Work Res. Pract., vol. 1, no. 3, pp. 261-283, Sep. 2002.

[64] Michael Quinn Patton, Qualitative Research \&amp; Evaluation Methods. Sage Publication, 2002. 
[65] F. Zamawe, "The Implication of Using NVivo Software in Qualitative Data Analysis: Evidence-Based Reflections," Malawi Med. J., vol. 27, no. 1, p. 13, Apr. 2015.

[66] Lyn Richards, Using NVIVO in Qualitative Research - Lyn Richards - Google Books. SAGE, 1999.

[67] S. Mannakkara and S. J. Wilkinson, "Supporting post-disaster social recovery to build back better," Int. J. Disaster Resil. Built Environ., vol. 6, no. 2, pp. 126-139, 2015.

[68] M. K. Lindell, "Recovery and reconstruction after disaster," in Encyclopedia of natural hazards, Springer, 2013, pp. 812-824.

[69] K. R. Grosskopf, "Post-disaster recovery and reconstruction safety training," Int. J. Disaster Resil. Built Environ., vol. 1, no. 3, pp. 322-333, 2010.

[70] R. A. Haslam et al., "Contributing factors in construction accidents," Appl. Ergon., vol. 36, pp. 401-415, 2005.

[71] A. S. Hanna, P. Peterson, and M.-J. Lee, "Benchmarking Productivity Indicators for Electrical/Mechanical Projects," J. Constr. Eng. Manag., vol. 128, no. 4, pp. 331-337, 2002.

[72] A. H. Abdul Rahim, A. M. Muhd Zaimi, and S. Bachan, "Causes of accidents at construction sites," Malaysian J. Civ. Eng., vol. 20, no. 2, pp. 242-259, 2008.

[73] E. Q. Ahonen, F. G. Benavides, and J. Benach, "Immigrant populations, work and health - a systematic literature review," Scandinavian Journal of Work, Environment \& Health, vol. 33. pp. 96-104, 2007.

[74] Central Bureau of Statistics, "REPORT ON THE NEPAL LABOUR FORCE SURVEY," 2008.

[75] S. Joshi, S. Shrestha, and S. Vaidya, "Occupational Safety and Health in Nepal," Int. J. Occup. Health Saf., vol. 1, 2011.

[76] The Conversation, "Nepal earthquake reconstruction won't succeed until the vulnerability of survivors is addressed," The Conversation, Online, pp. 1-5, 23Nov-2017.

[77] NRA, "NATIONAL RECONSTRUCTION AUTHORITY - Reconstruction Progress," 2018.

[78] NPC, "Nepal Earthquake 2015 Post Disaster Needs Assessment,” 2015.

[79] H. Hazarika, N. P. Bhandary, Y. Kajita, K. Kasama, K. Tsukahara, and R. K. Pokharel, "The 2015 Nepal Gorkha Earthquake: An overview of the damage, 
lessons learned and challenges," Lowl. Technol. Int., vol. 18, no. 2, pp. 105-118, 2016.

[80] M. A. Hashash et al., "Geotechnical Field Reconnaissance : Gorkha (Nepal) Earthquake of April 252015 and Related Shaking Sequence,” 2015.

[81] The Himalayan Times, “At Bhaktapur Durbar Square today," February 26, 2017, 2017. [Online]. Available: https://thehimalayantimes.com/kathmandu/bhaktapurdurbar-square-today/. [Accessed: 09-Nov-2018].

[82] N. Central Bureau of Statistics, “Official Summary of Census 2011,” 2011. [Online]. Available:

https://web.archive.org/web/20121202145804/http://cbs.gov.np/wpcontent/uploads/2012/11/Summary-Nepali.pdf. [Accessed: 09-Nov-2018].

[83] Nepal Labour Act 2074, "Nepal Labour Act 2074,” 2017.

[84] NRA, "Post Disaster Recovery Framework 2016-2020,” 2016.

[85] M. R. Hallowell, "Safety-Knowledge Management in American Construction Organizations," J. Manag. Eng., vol. 28, no. July, pp. 252-264, 2012.

[86] J. S. Petersen and C. Zwerling, "Comparison of health outcomes among older construction and blue-collar employees in the United States," Am. J. Ind. Med., vol. 34, no. 3, pp. 280-287, 1998.

[87] E. M. Rojas, Construction project management : a practical guide for building and electrical contractors. J. Ross Pub, 2009.

[88] M. Leung, I. Y. S. Chan, and J. Yu, "Preventing construction worker injury incidents through the management of personal stress and organizational stressors," Accid. Anal. Prev., vol. 48, pp. 156-166, Sep. 2012.

[89] Y. Neria, A. Nandi, and S. Galea, "Post-traumatic stress disorder following disasters: a systematic review," Psychol. Med., vol. 38, no. 04, pp. 467-480, Apr. 2008.

[90] Internal Displacement Monitoring Center, "GLOBAL DISASTER DISPLACEMENT RISK - A BASELINE FOR FUTURE WORK," IDMC, 2017. [Online]. Available: http://www.internal-displacement.org/publications/globaldisaster-displacement-risk-a-baseline-for-future-work. [Accessed: 27-May-2018].

[91] P. K. Freeman, "Allocation of post-disaster reconstruction financing to housing," Build. Res. Inf., vol. 32, no. 5, pp. 427-437, 2004.

[92] A. R. Kolbe et al., "Mortality, crime and access to basic needs before and after the haiti earthquake: A random survey of port-au-prince households," Med. Confl. Surviv., vol. 26, no. 4, pp. 281-297, 2010. 
[93] C. Roelofs, L. Sprague-Martinez, M. Brunette, and L. Azaroff, “A qualitative investigation of Hispanic construction worker perspectives on factors impacting worksite safety and risk," Environ. Heal. A Glob. Access Sci. Source, vol. 10, no. 1, pp. 1-9, 2011. 
APPENDICES 
Appendix 1. Questionnaire used for Interviews 


\section{SEMI STRUCTURED INTERVIEW QUESTIONNAIRE}

Name of the Interviewer:

Date:

Time:

Place of Interview:

\section{Q1. Tell me about your role and responsibilities in post-disaster} reconstruction.

- Associated Questions:

a) What do you do exactly?

b) What kinds of work are you involved in?

c) To what extent are you physically involved in your work?

d) Who assigned you to this work? (Contractor, Owner, Govt. or Self)

Q2. Tell me about your work experience.

- Associated Questions:

a) How long have you been working?

b) Have you ever changed your profession? What?

c) Do you like what you do? Why or why not?

d) Do you think you would change this profession in the future? What could be the reasons?

\section{Q3. Let's talk about the recent disaster you witnessed (if any).}

- Associate Questions:

a) What happened recently and when did it take place?

b) Were you somehow affected by the impact?

c) What are your losses by the impact?

\section{Q4. Please tell me about your experience in post disaster reconstruction.}

- Associate Questions:

a) How long have you been working in post disaster reconstruction?

b) Please tell me about other post-disaster reconstruction sites you worked in.

c) In what ways were these sites similar to from the sites you currently work in?

d) In what ways were these sites different from the sites you currently work in? 


\section{Q5. In what ways do you think PDR site is different from or similar to a regular construction site?}

- Associated Questions:

a) Please tell me more about the differences/similarities you faced in these two types of work sites.

b) What are the differences/similarities, if any, in terms of the site conditions itself?

c) What are the challenges you have faced in terms of working around the debris in the site?

d) What are the differences/similarities you have seen, if any, in terms of the construction method?

e) What are the differences/similarities you have seen, if any, in terms of equipment used in construction?

f) What are the differences/similarities you have seen, if any, in terms of supervision of construction?

g) What are the differences/similarities you have seen, if any, in terms of accidents?

h) What are the differences/similarities you have seen, if any, in terms of exposure to hazardous materials?

i) What are the differences/similarities you have seen, if any, in terms of illness that you have experienced?

j) What are the differences/similarities you have seen, if any, in terms of wages?

k) What are the differences/similarities you have seen, if any, in terms of time pressure to finish the construction?

1) What are the differences/similarities you have seen, if any, in terms of communication with clients (homeowners)?

m) What are the differences/similarities you have seen, if any, in terms of communication with other people who work with you in construction?

Q6. What are your main concerns related to your work in PDR sites?

- Associated Questions:

a) What are the main safety issues you faced in PDR sites that you think should be dealt with?

b) How are these safety issues being addressed now?

c) What measures would you take to ensure safety in PDR sites?

Q7. Do you think a PDR site is riskier than a regular construction site? 
Associated questions

a) Please tell me why you think a PDR site is riskier or not riskier than a regular construction site.

b) What are the physical risks that your work involves?

c) What are some of the health challenges you or your colleagues face in PDR? (that they have not faced before)

d) Do you get fatigued (more than usual) due to working longer hours or overtime?

e) What are the emotional challenges that your work involves?

f) What precautions does your employer take to address different types of risks we talked about?

g) What precautions do you take personally to address different types of risks we talked about?

\section{Q8. Let's talk about safety training and PPE in post disaster} reconstruction.

a) Have you received any special training prior to your work in PDR sites?

b) Where from did you get it? What was the training on (if not on safety)?

d) Do you think you have received sufficient Personal Protective Equipment (PPE)?

e) How do you think PPE could save you from potential accidents?

f) Please tell me about the training you received prior to your working in PDR.

g) If you were put in charge of training people involved in PDR, what would you train them on?

h) Please tell me why you would train them on these issues.

Q9. Please tell me why you chose to work in post-disaster reconstruction.

a) What motivated you to work on the reconstruction site (despite knowing the risks)?

b) Do you plan to work on the reconstruction site as long as it goes on?

\section{Q10. Do you think it's difficult for you to work as an immigrant? (If the} respondent is an immigrant)

- Associated Questions:

a. Do you face difficulties understanding the instructions?

b. How well do you communicate with your supervisor?

c. Do you face difficulty understanding the safety signs on sites? 
d. Being an immigrant, do you think you have been paid well? Equal to local workers, more or less?

e. Have you been provided with safety training and PPE?

f. Do you have to work extra hours? If yes, are you paid for that?

Else

What do you think about the immigrant workers who work on PDR sites?

a. Why do you think you need immigrant workers on site?

b. Is there a lack of workers after a disaster?

c. What challenges do you face while working with immigrant workers?

d. Do you pay them equal as local workers?

Q11. What are the emotional challenges that your work involves?

a) What are the challenges you face if you are away from your family?

b) What are the challenges of dealing with those who are affected by disasters?

c) Do you ever get depressed by the works on the reconstruction site, considering the devastation and wreckage?

d) What precautions does your employer take to address these challenges you face?

e) What precautions do you take personally to address these challenges you face?

f) How do you unwind after a draining workday?

Q11. What do you think about community involvement in reconstruction work?

a) Do the community people participate in the reconstruction work?

b) Do you think they have experience in construction works?

c) Does it help with what you are doing you or does it slow you down?

d) Do you think they are more exposed to construction hazards than experienced workers?

e) Have you witnessed any accident involving community people on the work site?

\section{Q12. Is there any urge/rush by the employer to finish your work earlier than standard required time?}

- Associated Questions:

a) Why do you think they are in a rush to finish the work? 
b) Do you think it affects your work or safety in any way?

c) Do you have to compromise with your safety or quality of the work?

d) Do you need to work extra hours to meet the need?

e) Do you get additional money for working extra hours?

f) How does working extra hours or rush to finish the work affect your physical and mental health?

\section{Q13. Tell us about some accidents that you or others have experienced in} PDR sites?

- Associated Questions:

a) How did this accident happen?

b) Was anyone hurt?

c) How serious was the injury?

d) Why do you think this accident take place?

e) How do you think this accident could have been prevented?

f) Do you have an authority to report to about any kind of accidents or hazards on the site?

g) What about the compensation or medical help after the accident?

\section{Q14. What was the safety situation before the disaster took place?}

- Associated Questions:

a) Do you think the rate of accident/hazards increased after a disaster?

b) What's your opinion about illness among workers while working (e.g., chemical contaminants)?

c) Have you been ill at the workplace or have you seen anyone getting in the workplace? How?

d) Did you get any safety training before the disaster? For regular construction?

e) What do you think about safety precautions? Are needed to be taken/ needed to be increased on reconstruction sites? And to the regular construction sites as well? 


\section{CLOSE ENDED QUESTIONS}

Q1. Name:

Q2. How old are you?

\begin{tabular}{|c|c|}
\hline Less than 18 & $\square \quad 56-50$ \\
\hline $18-25$ & $\square \quad 50-55$ \\
\hline $26-30$ & $\square \quad 56-60$ \\
\hline $31-35$ & $61-65$ \\
\hline $36-40$ & Above 65 \\
\hline
\end{tabular}

Q3. Gender
Male
Female
Others

Q4. Educational Qualification
Less than $12^{\text {th }}$ grade
High School
Bachelor's Degree
Attended college but no degree
Graduate Degree
Professional Degree
Associated Degree (e.g. AA, AS)
Others

Q5. Nationality:

Q6. What is your ethnicity?

Q7. Race:

$\checkmark$ White

Asian

African American

Dative Islander

American Indian

Others

Do not know

Q8. Occupation:

Q9. Experience in Construction:

Less than 1 year

- 3 years to 6 years

$\square \quad 9$ years to 12 years
1 year to 3 years

6 years to 9 years

More than 12 years 
Q10. Present

Address:

Q11. Preferred Language(s):

First Language

:

Second Language :

Third Language 